Supporting Information for

\title{
Synthesis of (-)-Agelastatin A by [3.3] Sigmatropic Rearrangement of Allyl Cyanate
}

\author{
Yoshiyasu Ichikawa,* Tomonori Yamaoka, \\ Keiji Nakano, Hiyoshizo Kotsuki \\ Faculty of Science, Kochi University, Akebono-cho, Kochi 780-8520 \\ Tel: +81-88-844-8292, FAX: +81-88-844-8359 \\ E-mail: ichikawa@kochi-u.ac.jp
}

I. Calculation of the $\mathrm{p} K_{\mathrm{a}}$ of pyrrole nitrogen

II. Experimental Procedures and Characterization Data for compounds 1, 7, 8, 9, 11, 12, 13,

14, 19, 20a, 24, 26, 27, 29 and 31

III. References

16

VI. ${ }^{1} \mathrm{H}$ and ${ }^{13} \mathrm{C}$ NMR Spectra for All Relevant Compounds 


\section{Calculation of the $\mathrm{p} K_{\mathrm{a}}$ of pyrrole nitrogen}

In the first total synthesis of $( \pm$ )-agelastatin A (Scheme 1 ), Weinreb reported the B-ring annulation using base-catalyzed intramolecular Michael addition in acceptable yield $(61 \%){ }^{1}$

Scheme 1

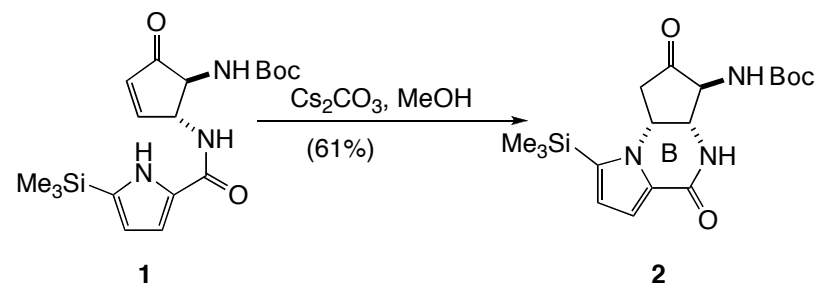

Davies found that treatment of 3 with 10 equiv of $\mathrm{Cs}_{2} \mathrm{CO}_{3}$ in $\mathrm{MeOH}$ for 16 min resulted in a $68 \%$ yield of the desired 4 along with trace amounts of cyclopentenone 5 (Scheme 2). ${ }^{2}$ Longer reaction times, $2 \mathrm{~h}$, produced the enone $\mathbf{5}$ as the major product.

Scheme 2

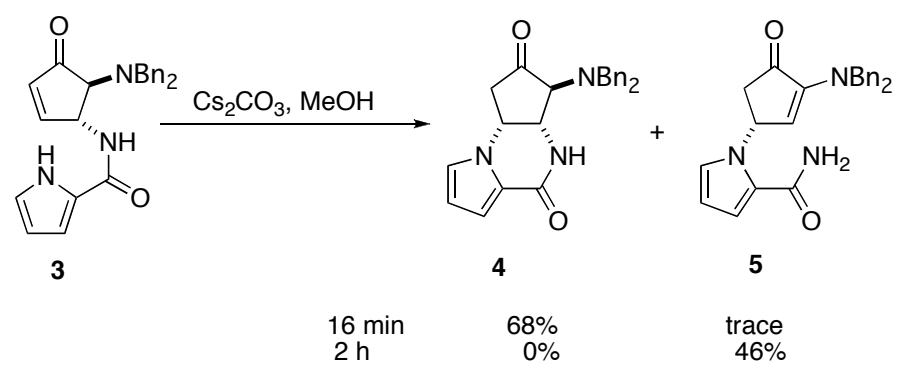

We considered that the above two examples show that the special caution and high experimental techniques are necessary for the B-ring synthesis. In this sense, Hale's experiments appeared to be quite instructive (Scheme 3). ${ }^{3}$ Hale noted that B-ring construction was quite problematic due to the facile cyclopentenone isomerization; for example, treatment of $\mathbf{6}$ with DBU in THF gave the enone $\mathbf{7}$ predominantly. To avoid this obstacle, enone $\mathbf{6}$ was treated with $N$-bromosuccinimide to afford a multi-component mixture of mono-, di-, and tribromopyrroles; however, addition of Hünigh base to the reaction mixture brought about the requisite Michael ring closure to provide 8 . 
Scheme 3

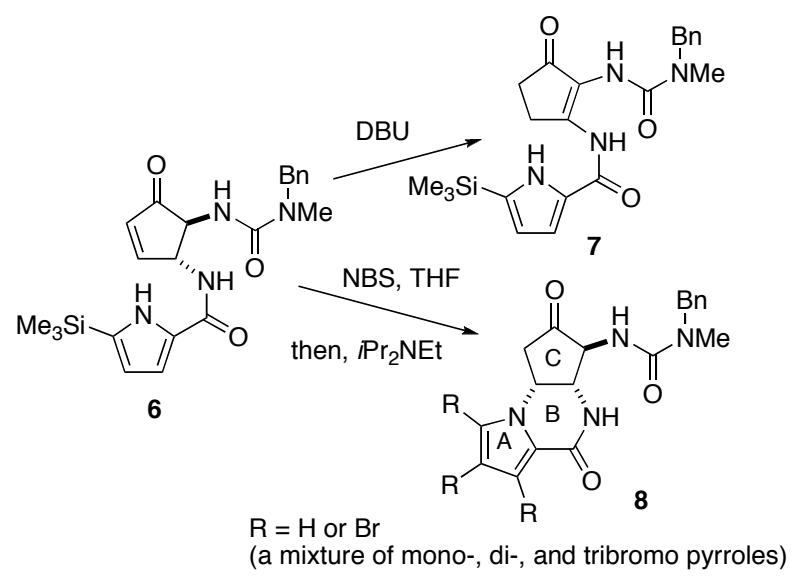

These experiments clearly suggest that introduction of electron-withdrawing group to the pyrrole A-ring would lower the $\mathrm{p} K_{\mathrm{a}}$ of pyrrole nitrogen, which could circumvent the cyclopentenone isomerization problem during base-catalyzed ring closure. Given these considerations, a plan to link the bromopyrrole directly to the cyclopentenone core emerged. To estimate the electron-withdrawing effect of the bromine substituent, we calculated the $\mathrm{p} K_{\mathrm{a}}$ values of pyrrole $\mathrm{N}-\mathrm{H}$ (Figure 1) using Advanced Chemistry Development (ACD/Labs) software V 8.14 for Solaris (1994-2006 ACD/LABS), which revealed that the introduction of one bromine substituent enhances acidity by approximately $1.7 \mathrm{p} K_{\mathrm{a}}$ unit and two bromine atoms produce an approximately 450 -fold lowering in $\mathrm{N}-\mathrm{H} \mathrm{p} K_{\mathrm{a}}$ value.

Figure 1 Effect of the bromine substituent on lowering $\mathrm{p} K_{\mathrm{a}}$ of pyrrole $\mathrm{N}-\mathrm{H}$
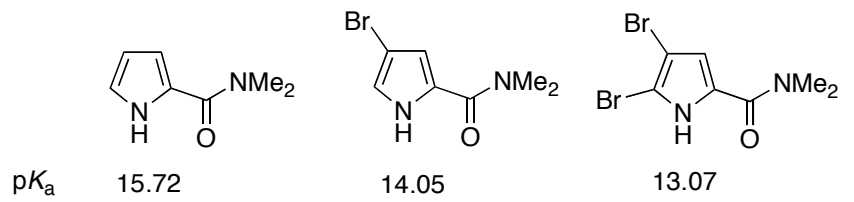


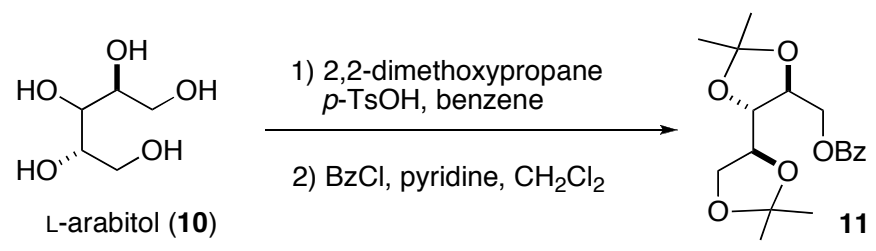

1-O-Benzoyl-2,3:4,5-Di- $\boldsymbol{O}$-(1-methylethylidene)-L-arabinitol 11: To a solution of L-arabitol 10 (2.05 g, $13.5 \mathrm{mmol})$, 2,2-dimethoxypropane (16.6 ml, $134.8 \mathrm{mmol})$ and $p$-TsOH $(13 \mathrm{mg}, 0.07 \mathrm{mmol})$ in benzene $(45.0 \mathrm{ml})$ was heated at $75^{\circ} \mathrm{C}$ for $14.5 \mathrm{~h}$. The resulting raction mixture was treated with triethylamine $(0.10 \mathrm{ml}, 0.7 \mathrm{mmol})$ and then concentrated to afford the residue, which was loaded on a short column of silica gel and then eluted with AcOEt. The effluent was collected and then concentrated under reduced pressure. The resultant acetonide $(3.20 \mathrm{~g})$ was dissolved in pyridine $(10.0 \mathrm{ml})$ and dichloromethane $(40.0 \mathrm{ml})$, and then was treated with benzoyl chloride $(1.44 \mathrm{ml}$, $12.4 \mathrm{mmol}$ ) at $0{ }^{\circ} \mathrm{C}$. After stirring at room temperature for $35 \mathrm{~min}$, $N, N$-dimethyl-1,3-propandiamine $(0.50 \mathrm{ml}, 4.1 \mathrm{mmol})$ was added. After stirring at room temperature for $15 \mathrm{~min}$, the reaction mixture was diluted with $\mathrm{Et}_{2} \mathrm{O}(100 \mathrm{ml})$, and then was washed with $1 \mathrm{~N} \mathrm{HCl}$, saturated aqueous $\mathrm{NaHCO}_{3}$, brine and dried over anhydrous $\mathrm{Na}_{2} \mathrm{SO}_{4}$. Concentration under reduced pressure gave the residue, which was purified by silica gel chromatography (1:3 AcOEt/hexane) to afford the benzoate $11(3.71 \mathrm{~g}, 80 \%)$ as a colorless oil: $[\alpha]_{\mathrm{D}}{ }^{20}=-15.7\left(\right.$ c 5.40, $\left.\mathrm{CHCl}_{3}\right)$; IR $(\mathrm{NaCl}) v_{\max }$ 2987, $1724 \mathrm{~cm}^{-1} ;{ }^{1} \mathrm{H}$ NMR $\left(\mathrm{CDCl}_{3}, 400 \mathrm{MHz}\right) \delta 1.33(3 \mathrm{H}, \mathrm{s}), 1.38(3 \mathrm{H}, \mathrm{s}), 1.42(3 \mathrm{H}, \mathrm{s})$, $1.43(3 \mathrm{H}, \mathrm{s}), 3.87(1 \mathrm{H}, \mathrm{t}, J=8.1), 4.01(1 \mathrm{H}, \mathrm{dd}, J=8.3,4.0), 4.11(1 \mathrm{H}, \mathrm{ddd}, J=8.1,6.1$, 4.0), 4.16 (1H, dd, $J=8.3,6.1$ ), 4.30 (1H, ddd, $J=8.1,5.4,3.0), 4.41$ (1H, dd, $J=12.0$, 5.4), $4.67(1 \mathrm{H}, \mathrm{dd}, J=12.0,3.0), 7.40-8.20(5 \mathrm{H}) ;{ }^{13} \mathrm{C} \mathrm{NMR}\left(\mathrm{CDCl}_{3}, 100 \mathrm{MHz}\right) \delta 25.1$, 26.7, 26.97, 27.04, 64.6, 67.7, 77.1, 77.6, 78.5, 109.8, 110.0, 128.3, 129.6, 129.9, 133.0, 166.3. Anal. Calcd for $\mathrm{C}_{18} \mathrm{H}_{24} \mathrm{O}_{6}$ : C, 64.27; H, 7.19. Found: C, 64.31; H, 7.37.

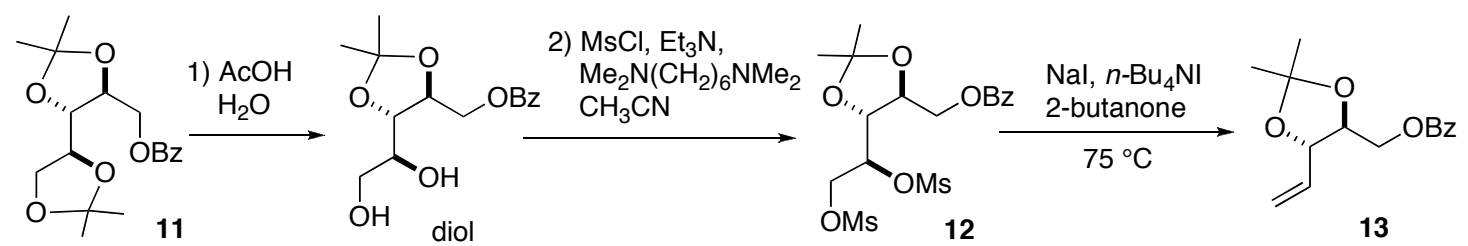

1-O-Benzoyl-4,5-dideoxy-2,3-O-(1-methylethylidene)-L-threo-pent-4-enitol 13: A solution of benzoate $10(7.55 \mathrm{~g}, 22.3 \mathrm{mmol})$ in $\mathrm{H}_{2} \mathrm{O}(30.0 \mathrm{ml})$ and $\mathrm{AcOH}(90.0 \mathrm{ml})$ was stirred at room temperature for $8 \mathrm{~h}$, and the reaction mixture was poured into saturated 
aqueous $\mathrm{NaHCO}_{3}$. The aqueous layer was extracted with $\mathrm{Et}_{2} \mathrm{O}$ (3 times) and the combined organic layer was washed with saturated aqueous $\mathrm{NaHCO}_{3}$, brine and dried over anhydrous $\mathrm{Na}_{2} \mathrm{SO}_{4}$. Concentration under reduced pressure provided the diol (5.23 $\mathrm{g}):[\alpha]_{\mathrm{D}}{ }^{20}=-13.6\left(c 5.10, \mathrm{CHCl}_{3}\right)$; IR $(\mathrm{NaCl}) v_{\max } 3440,2987,1720 \mathrm{~cm}^{-1} ;{ }^{1} \mathrm{H} \mathrm{NMR}$ $\left(\mathrm{CDCl}_{3}, 400 \mathrm{MHz}\right) \delta 1.41(3 \mathrm{H}, \mathrm{s}), 1.42(3 \mathrm{H}, \mathrm{s}), 2.76(1 \mathrm{H}, \mathrm{br}), 3.32(1 \mathrm{H}, \mathrm{brd}, J=4.9$ $\mathrm{Hz}), 3.69-3.88(3 \mathrm{H}), 3.90(1 \mathrm{H}, \mathrm{t}, J=7.5 \mathrm{~Hz}), 4.36(1 \mathrm{H}, \mathrm{ddd}, J=7.5,5.6,2.4 \mathrm{~Hz})$, $4.43(1 \mathrm{H}, \mathrm{dd}, J=12.0,5.6 \mathrm{~Hz}), 4.67(1 \mathrm{H}, \mathrm{dd}, J=12.0,2.4 \mathrm{~Hz}), 7.41-8.08(5 \mathrm{H}) ;{ }^{13} \mathrm{C}$ $\mathrm{NMR}\left(\mathrm{CDCl}_{3}, 100 \mathrm{MHz}\right) \delta$ 26.94, 27.03, 63.9, 65.4, 72.9, 77.0, 77.9, 109.9, 128.4, 129.6, 129.7, 133.2, 166.8. Anal. Calcd for $\mathrm{C}_{15} \mathrm{H}_{20} \mathrm{O}_{6}: \mathrm{C}, 60.80 ; \mathrm{H}, 6.80$. Found: $\mathrm{C}$, $61.09 ; \mathrm{H}, 7.03$.

The resultant diol, triethylamine $(29.4 \mathrm{ml}, 211 \mathrm{mmol})$ and $N, N, N^{\prime}, N^{\prime}-$ tetramethyl-1,6-hexanediamine $(1.51 \mathrm{ml}, 7.06 \mathrm{mmol})$ in acetonitrile $(70.0 \mathrm{ml})$ cooled to $-10{ }^{\circ} \mathrm{C}$ was added methanesulfonyl chloride $(8.20 \mathrm{ml} 105.9 \mathrm{mmol})$, and the cooling bath was removed. After stirring at room temperature for $2 \mathrm{~h}$, the reaction mixture was cooled $0{ }^{\circ} \mathrm{C}$ and then treated with $N, N$-dimethyl-1,3-propanediamine $(12.2 \mathrm{ml}, 97.2$ mmol). After being stirred at room temperature for $30 \mathrm{~min}, \mathrm{H}_{2} \mathrm{O}(100 \mathrm{ml})$ was added. The separated aqueous layer was extracted with $\mathrm{Et}_{2} \mathrm{O}$ (3 times), and the combined organic layer was washed with $0.3 \mathrm{~N} \mathrm{HCl}$, saturated aqueous $\mathrm{NaHCO}_{3}$, brine and dried over anhydrous $\mathrm{Na}_{2} \mathrm{SO}_{4}$. Concentration under reduced pressure provided the dimesylate 12 (9.43 g): $[\alpha]_{\mathrm{D}}{ }^{19}=-20.6$ (c 1.40, $\left.\mathrm{CHCl}_{3}\right)$; IR $(\mathrm{NaCl}) v_{\max } 3030,1720$, 1359, $1176 \mathrm{~cm}^{-1} ;{ }^{1} \mathrm{H}$ NMR $\left(\mathrm{CDCl}_{3}, 400 \mathrm{MHz}\right) \delta 1.45(6 \mathrm{H}, \mathrm{s}), 3.09(3 \mathrm{H}, \mathrm{s}), 3.17(3 \mathrm{H}, \mathrm{s})$, $4.15(1 \mathrm{H}, \mathrm{t}, J=7.3 \mathrm{~Hz}), 4.40-4.49(3 \mathrm{H}), 4.63-4.68(2 \mathrm{H}), 4.93(1 \mathrm{H}, \mathrm{ddd}, J=7.7,5.5$, $2.4 \mathrm{~Hz}), 7.40-8.10(5 \mathrm{H}) ;{ }^{13} \mathrm{C} \mathrm{NMR}\left(\mathrm{CDCl}_{3}, 100 \mathrm{MHz}\right) \delta 26.9,27.0,37.6,38.8,64.1$, 67.7, 74.3, 77.5, 77.7, 111.2, 128.4, 129.5, 129.7, 133.2, 166.1. Anal. Calcd for $\mathrm{C}_{17} \mathrm{H}_{24} \mathrm{O}_{10} \mathrm{~S}_{2}$ : C, 45.12; H, 5.35. Found: C, 45.04; H, 5.72.

A solution of dimesylate 12, sodium iodide $(23.6 \mathrm{~g}, 159 \mathrm{mmol})$ and tetrabutylammonium iodide $(5.90 \mathrm{~g}, 15.9 \mathrm{mmol})$ dissolved in 2-butanone $(100 \mathrm{ml})$ was heated at $75{ }^{\circ} \mathrm{C}$ for $20 \mathrm{~h}$. The reaction mixture was diluted with $\mathrm{Et}_{2} \mathrm{O}(100 \mathrm{ml})$ and aqueous $3 \mathrm{M} \mathrm{Na}_{2} \mathrm{SO}_{3}(150 \mathrm{ml})$. After stirring at room temperature for $30 \mathrm{~min}$, separated aqueous layer was extracted with $\mathrm{Et}_{2} \mathrm{O}$ (3 times), and the combined organic layer was washed with $\mathrm{H}_{2} \mathrm{O}$, brine and dried over $\mathrm{Na}_{2} \mathrm{SO}_{4}$. Concentration under reduced pressure provided the residue, which was purified by silica gel chromatography (1:4 AcOEt/hexane) to afford alkene $13(3.53 \mathrm{~g}, 60 \%)$ as a colorless oil: $[\alpha]_{\mathrm{D}}{ }^{16}=+1.2$ (c 4.40, $\left.\mathrm{CHCl}_{3}\right)$; IR $(\mathrm{NaCl}) v_{\max } 2987,1724 \mathrm{~cm}^{-1} ;{ }^{1} \mathrm{H} \mathrm{NMR}\left(\mathrm{CDCl}_{3}, 400 \mathrm{MHz}\right) \delta 1.46$ 
$(3 \mathrm{H}, \mathrm{s}), 1.47$ (3H, s), $4.06(1 \mathrm{H}, \mathrm{ddd}, J=8.3,5,3,3.8 \mathrm{~Hz}), 4.34(1 \mathrm{H}, \mathrm{dd}, J=8.3,7.3 \mathrm{~Hz})$, $4.40(1 \mathrm{H}, \mathrm{dd}, J=12.0,5.3 \mathrm{~Hz}), 4.54(1 \mathrm{H}, \mathrm{dd}, J=12.0,3.8 \mathrm{~Hz}), 5.30(1 \mathrm{H}, \mathrm{dt}, J=10.2$, $1.2 \mathrm{~Hz}), 5.43(1 \mathrm{H}, \mathrm{dt}, J=17.1,1.2 \mathrm{~Hz}), 5.89(1 \mathrm{H}, \mathrm{ddd}, J=17.1,10.2,7.3 \mathrm{~Hz}), 7.42-$ $8.08(5 \mathrm{H}) ;{ }^{13} \mathrm{C} \mathrm{NMR}\left(\mathrm{CDCl}_{3}, 100 \mathrm{MHz}\right) \delta 26.9,27.0,63.5,77.2,78.6,79.5,109.8$, 119.5, 128.4, 129.7, 133.2, 134.7, 166.3. Anal. Calcd for $\mathrm{C}_{15} \mathrm{H}_{18} \mathrm{O}_{4}$ : C, 68.68; H, 6.92. Found: C, 68.69; H, 7.22.
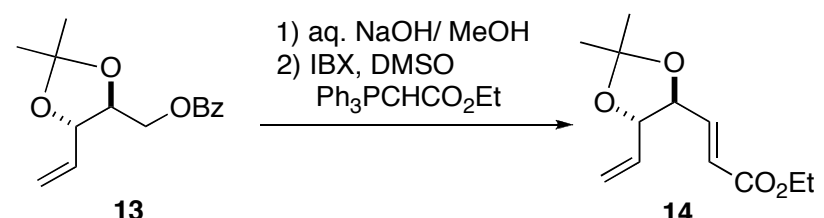

Ethyl 3-[(4S,5S)-2,2-dimethyl-5-vinyl-1,3-dioxolan-4-yl]acrylate 14: To a solution of alkene $13(6.65 \mathrm{~g}, 25.4 \mathrm{mmol})$ in $\mathrm{MeOH}(50.0 \mathrm{ml})$ was added $1 \mathrm{~N} \mathrm{NaOH}(27.8 \mathrm{ml})$, and then was stirred at room temperature for $1.5 \mathrm{~h}$. The solution was extracted with $\mathrm{Et}_{2} \mathrm{O}$ (3 times) and the combined organic layer was washed with brine and dried over anhydrous $\mathrm{Na}_{2} \mathrm{SO}_{4}$. Concentration under reduced pressure provided the volatile alcohol (4.94 g), which was dissolved in DMSO $(120 \mathrm{ml})$. (Carbethoxymethylene)triphenylphosphorane (17.6 g, $50.7 \mathrm{mmol})$ and IBX (17.8 g, $63.4 \mathrm{mmol}$ ) was added. After stirring at room temperature for $15 \mathrm{~h}$, the reaction mixture was diluted with $\mathrm{H}_{2} \mathrm{O}(120 \mathrm{ml})$. The aqueous layer was extracted with $\mathrm{Et}_{2} \mathrm{O}(3$ times) and the combined organic layer was washed with $\mathrm{H}_{2} \mathrm{O}$, brine and dried over anhydrous $\mathrm{Na}_{2} \mathrm{SO}_{4}$. Concentration under reduced pressure provided the residue, which was purified by silica gel chromatography (1:4 AcOEt/hexane) to afford $\alpha, \beta$-unsaturated ester $14(4.41 \mathrm{~g}, 77 \%)$ as colorless oil: $[\alpha]_{\mathrm{D}}{ }^{20}=+14.8\left(c 1.00, \mathrm{CHCl}_{3}\right)$; IR $(\mathrm{NaCl}) v_{\max } 2987,1725 \mathrm{~cm}^{-1} ;{ }^{1} \mathrm{H} \mathrm{NMR}\left(\mathrm{CDCl}_{3}, 400 \mathrm{MHz}\right) \delta \quad 1.30(3 \mathrm{H}, \mathrm{t}, J=7.1$ $\mathrm{Hz}), 1.46(3 \mathrm{H}, \mathrm{s}), 1.47(3 \mathrm{H}, \mathrm{s}), 4.14(1 \mathrm{H}, \mathrm{brdd}, J=8.5,7.1 \mathrm{~Hz}), 4.21(2 \mathrm{H}, \mathrm{q}, J=7.1)$, $4.25(1 \mathrm{H}, \mathrm{ddd}, J=8.5,5.4,1.4 \mathrm{~Hz}), 5.32(1 \mathrm{H}, \mathrm{dt}, J=10.5,1.0 \mathrm{~Hz}), 5.41(1 \mathrm{H}, \mathrm{dt}, J=$ $17.2,1.0 \mathrm{~Hz}), 5.84(1 \mathrm{H}, \mathrm{ddd}, J=17.2,10.5,7.1 \mathrm{~Hz}), 6.12(1 \mathrm{H}, \mathrm{dd}, J=15.6,1.4 \mathrm{~Hz})$, $6.87(1 \mathrm{H}, \mathrm{dd}, J=15.6,5.4 \mathrm{~Hz}) ;{ }^{13} \mathrm{C} \mathrm{NMR}\left(\mathrm{CDCl}_{3}, 100 \mathrm{MHz}\right) \delta 14.2,26.7,26.9,60.6$, 79.9, 82.1, 110.0, 119.9, 122.8, 133.5, 142.7, 165.9. Anal. Calcd for $\mathrm{C}_{12} \mathrm{H}_{18} \mathrm{O}_{4}: \mathrm{C}$, 63.70; H, 8.02. Found: C, 63.92; H, 8.42. 


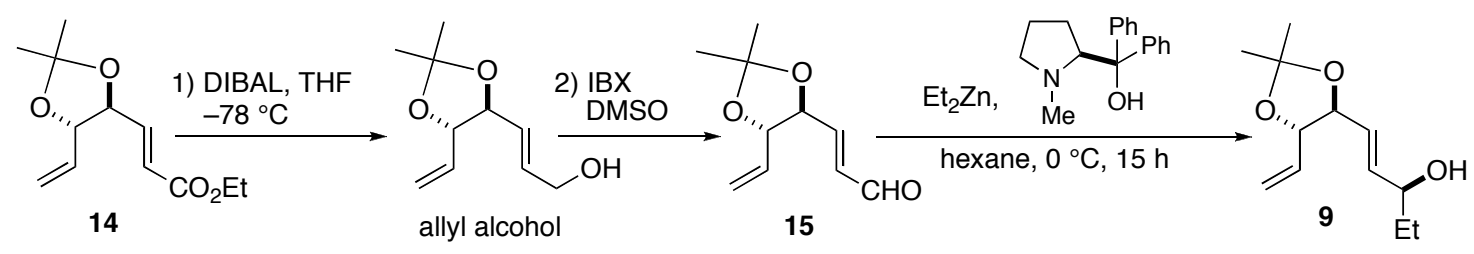

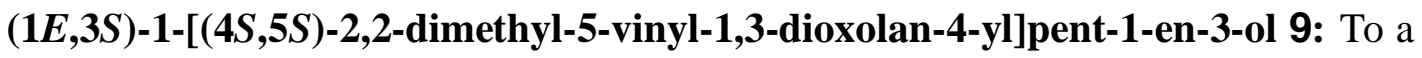
solution of $\alpha, \beta$-unsaturated ester $14(181 \mathrm{mg}, 0.80 \mathrm{mmol})$ in THF $(3.0 \mathrm{ml})$ cooled to $-78{ }^{\circ} \mathrm{C}$ was added DIBAL (3.4 ml, $3.20 \mathrm{mmol}, 0.94 \mathrm{~mol} / \mathrm{l}$ in hexane). After stirring at $-78{ }^{\circ} \mathrm{C}$ for $2 \mathrm{~h}$, the solution was diluted with $1 \mathrm{M} \mathrm{KHSO}_{4}$ and aqueous potassium sodium (+)-tartrate tetrahydrate solution. After stirring at room temperature for $1.5 \mathrm{~h}$, the aqueous layer was extracted with $\mathrm{Et}_{2} \mathrm{O}$ (3 times). The combined organic layer was washed with water and saturated aqueous $\mathrm{NaHCO}_{3}$, brine, and dried over anhydrous $\mathrm{Na}_{2} \mathrm{SO}_{4}$. Concentration under reduced pressure provided the residue, which was purified by silica gel chromatography (1:2 AcOEt/hexane) to afford the allyl alcohol $(139 \mathrm{mg}, 95 \%)$ as a colorless oil: $[\alpha]_{\mathrm{D}}{ }^{20}=+30.4\left(c 1.30, \mathrm{CHCl}_{3}\right)$; IR $(\mathrm{NaCl}) v_{\max } 3422$ $\mathrm{cm}^{-1} ;{ }^{1} \mathrm{H} \mathrm{NMR}\left(\mathrm{CDCl}_{3}, 400 \mathrm{MHz}\right) \delta 1.44(6 \mathrm{H}, \mathrm{s}), 2.60(1 \mathrm{H}, \mathrm{br}), 4.07-4.17(4 \mathrm{H}), 5.26$ $(1 \mathrm{H}, \mathrm{brd}, J=10.5 \mathrm{~Hz}), 5.36(1 \mathrm{H}, \mathrm{brd}, J=17.1 \mathrm{~Hz}), 5.70(1 \mathrm{H}, \mathrm{brdd}, J=15.6,6.6 \mathrm{~Hz})$, $5.80(1 \mathrm{H}, \mathrm{ddd}, J=17.1,10.5,6.6 \mathrm{~Hz}), 5.95(1 \mathrm{H}, \mathrm{dt}, J=15.6,5.1 \mathrm{~Hz}) ;{ }^{13} \mathrm{C} \mathrm{NMR}\left(\mathrm{CDCl}_{3}\right.$, $100 \mathrm{MHz}) \delta 26.84,26.87,62.2,81.2,82.1,109.0,119.0,126.1,133.8,134.3$. Anal. Calcd for $\mathrm{C}_{10} \mathrm{H}_{16} \mathrm{O}_{3}: \mathrm{C}, 65.19 ; \mathrm{H}, 8.75$. Found: C, 65.04; $\mathrm{H}, 9.03$.

To a solution of the allyl alcohol $(81 \mathrm{mg}, 0.44 \mathrm{mmol})$ in DMSO $(2.0 \mathrm{ml})$ was added IBX (185 mg, $0.66 \mathrm{mmol})$ in one portion. After stirring at room temperature for $10 \mathrm{~h}$, the solution was diluted with $\mathrm{Et}_{2} \mathrm{O}(5 \mathrm{ml})$ and $\mathrm{H}_{2} \mathrm{O}(5 \mathrm{ml})$, and the stirring was continued for $30 \mathrm{~min}$. The aqueous layer was extracted with $\mathrm{Et}_{2} \mathrm{O}$ (3 times) and the combined organic layer was washed with water, brine, and dried over anhydrous $\mathrm{Na}_{2} \mathrm{SO}_{4}$. Concentration under reduced pressure provided the residue, which was purified by silica gel chromatography (1:5 AcOEt/hexane) to afford $\alpha, \beta$-unsaturated aldehyde 15 (77 mg, 96\%) as a colorless oil, which was immediately used for the next reaction.

To a solution of the $\alpha, \beta$-unsaturated aldehyde $15(77 \mathrm{mg}, 0.42 \mathrm{mmol})$ and $(S)-(+)-D P M P M(21 \mathrm{mg}, 0.08 \mathrm{mmol})$ in hexane $(1.0 \mathrm{ml})$ cooled to $0{ }^{\circ} \mathrm{C}$ was added diethylzinc $(1.01 \mathrm{M}$ solution in hexane, $0.92 \mathrm{ml}, 0.92 \mathrm{mmol})$. After stirring at $0{ }^{\circ} \mathrm{C}$ for $16 \mathrm{~h}$, the mixture was diluted with $\mathrm{Et}_{2} \mathrm{O}$ and poured into $1 \mathrm{M}$ aqueous $\mathrm{KHSO}_{4}$ solution. The aqueous layer was extracted with $\mathrm{Et}_{2} \mathrm{O}$ (3 times). The combined organic layer was 
washed with saturated aqueous $\mathrm{NaHCO}_{3}$, brine, dried over anhydrous $\mathrm{Na}_{2} \mathrm{SO}_{4}$ and then concentrated under reduced pressure. The resulting residue was purified by silica gel chromatography (1:5 AcOEt/hexane) to afford allyl alcohol 9 (83mg, 92\%) as a colorless oil. Diastereoslectivity was determined to be $93: 7$ by acetylation of 9 and ${ }^{1} \mathrm{H}$ NMR analysis of the resultant crude products: $[\alpha]_{\mathrm{D}}{ }^{19}=-37.8\left(c 0.85, \mathrm{CHCl}_{3}\right)$; IR $(\mathrm{NaCl}) v_{\max } 3433 \mathrm{~cm}^{-1} ;{ }^{1} \mathrm{H} \mathrm{NMR}\left(\mathrm{CDCl}_{3}, 400 \mathrm{MHz}\right) \delta 0.93(3 \mathrm{H}, \mathrm{t}, J=7.5 \mathrm{~Hz}), 1.45$ $(6 \mathrm{H}, \mathrm{s}), 1.56(2 \mathrm{H}, \mathrm{dqn}, J=7.5,2.0 \mathrm{~Hz}), 1.68(1 \mathrm{H}, \mathrm{br}), 4.06-4.14(3 \mathrm{H}), 5.26(1 \mathrm{H}, \mathrm{dq}, J$ $=10.2,0.7 \mathrm{~Hz}), 5.36(1 \mathrm{H}, \mathrm{dt}, J=17.1,1.2 \mathrm{~Hz}), 5.67(1 \mathrm{H}, \mathrm{ddd}, J=15.5,6.8,1.2 \mathrm{~Hz})$,

5.75-5.87 (2H); ${ }^{13} \mathrm{C} \mathrm{NMR}\left(\mathrm{CDCl}_{3}, 100 \mathrm{MHz}\right) \delta$ 9.5, 26.95, 26.98, 29.9, 73.0, 81.4, 82.4, 109.1, 119.0, 126.0, 134.0, 137.8. Anal. Calcd for $\mathrm{C}_{12} \mathrm{H}_{20} \mathrm{NO}_{3}$ : C, 67.89; H, 9.50. Found: C, 68.06; H, 9.90.

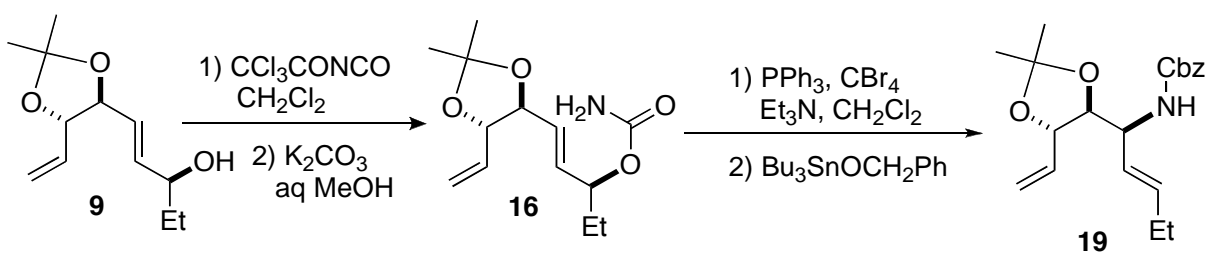

\section{Benzyl \{(1S,2E)-1-[(4S,5S)-2,2-dimethyl-5-vinyl-1,3-dioxolan-4-yl]pent-2-en-1-} yl \} carbamate 19: To a solution of allyl alcohol 9 (513 mg, $2.42 \mathrm{mmol}$ ) in $\mathrm{CH}_{2} \mathrm{Cl}_{2}$ $(29.0 \mathrm{ml})$ cooled to $0{ }^{\circ} \mathrm{C}$ was added trichloroacetyl isocyanate $(0.56 \mathrm{ml}, 4.84 \mathrm{mmol})$. After stirring at $0{ }^{\circ} \mathrm{C}$ for $25 \mathrm{~min}$, the solution was concentrated under reduced pressure. The resulting residue was dissolved in a mixture of $\mathrm{MeOH}(14.5 \mathrm{ml})$ and $1 \mathrm{M}$ aqueous potassium carbonate $(14.5 \mathrm{ml})$, and then was stirred at room temperature for $5 \mathrm{~h}$. The aqueous layer was extracted with $\mathrm{Et}_{2} \mathrm{O}$ (3 times) and the combined organic layer was washed with brine and dried over anhydrous $\mathrm{Na}_{2} \mathrm{SO}_{4}$. Concentration under reduced pressure provided the crude carbamate $16\left(996 \mathrm{mg}\right.$ ), which was dissolved in $\mathrm{CH}_{2} \mathrm{Cl}_{2}$ $(17.0 \mathrm{ml})$. To this solution was added triphenylphosphine $(1.91 \mathrm{~g}, 7.26 \mathrm{mmol})$ and triethylamine $(3.0 \mathrm{ml}, 21.8 \mathrm{mmol})$. To this solution cooled to $-10{ }^{\circ} \mathrm{C}$ was added a solution of carbon tetrabromide $(2.81 \mathrm{~g}, 8.47 \mathrm{mmol})$ in $\mathrm{CH}_{2} \mathrm{Cl}_{2}(23.0 \mathrm{ml})$ dropwise. After being stirred at $-10{ }^{\circ} \mathrm{C}$ for $1.5 \mathrm{~h}, \mathrm{Bu}_{3} \mathrm{SnOCH}_{2} \mathrm{Ph}(2.20 \mathrm{ml}, 7.26 \mathrm{mmol})$ was added. The resulting reaction mixture was allowed to warm to room temperature. After stirring at room temperature for $24 \mathrm{~h}$, succinic anhydride $(727 \mathrm{mg}, 7.26 \mathrm{mmol})$ was added. After being stirred at room temperature for $2 \mathrm{~h}$, the mixture was diluted with $\mathrm{Et}_{2} \mathrm{O}$, and then washed with $1 \mathrm{M} \mathrm{KHSO}_{4}$, water, saturated aqueous $\mathrm{NaHCO}_{3}$ and brine. After being dried over anhydrous $\mathrm{Na}_{2} \mathrm{SO}_{4}$ and concentration under reduced pressure, the 
resultant residue was dissolved in acetonitrile $(10.0 \mathrm{ml})$, and then treated with potassium fluoride $(580 \mathrm{mg}, 10.0 \mathrm{mmol}$ ). After being stirred at room temperature for $24 \mathrm{~h}$, the reaction mixture was diluted with $\mathrm{Et}_{2} \mathrm{O}$, washed with water, brine and dried over anhydrous $\mathrm{Na}_{2} \mathrm{SO}_{4}$. Concentration under reduced pressure gave the residue, which was purified by silica gel chromatography (1:6 AcOEt/hexane) to afford benzyl carbamate $19(706 \mathrm{mg}, 85 \%)$ as a colorless oil: $[\alpha]_{\mathrm{D}}{ }^{15}=-14.7\left(c 0.86, \mathrm{CHCl}_{3}\right)$; IR $(\mathrm{NaCl}) v_{\max } 3330,2985,1720 \mathrm{~cm}^{-1} ;{ }^{1} \mathrm{H} \mathrm{NMR}\left(\mathrm{CDCl}_{3}, 400 \mathrm{MHz}\right) \delta 1.00(3 \mathrm{H}, \mathrm{t}, J=7.3$ $\mathrm{Hz}), 1.38(3 \mathrm{H}, \mathrm{s}), 1.40(3 \mathrm{H}, \mathrm{s}), 2.08(2 \mathrm{H}$, quin, $J=7.3 \mathrm{~Hz}), 3.79(1 \mathrm{H}, \mathrm{dd}, J=8.1,3.9$ $\mathrm{Hz}), 4.20(1 \mathrm{H}, \mathrm{t}, J=8.1 \mathrm{~Hz}), 4.24(1 \mathrm{H}, \mathrm{br}), 5.06(1 \mathrm{H}, \mathrm{d}, J=12.3 \mathrm{~Hz}), 5.11(1 \mathrm{H}, \mathrm{d}, J=$ $12.3 \mathrm{~Hz}), 5.24(1 \mathrm{H}, \mathrm{d}, J=10.4 \mathrm{~Hz}), 5.31(1 \mathrm{H}, \mathrm{d}, J=17.3 \mathrm{~Hz}), 5.41(1 \mathrm{H}, \mathrm{br}), 5.47(1 \mathrm{H}$, $\mathrm{dd}, J=15.6,7.3 \mathrm{~Hz}), 5.75(1 \mathrm{H}, \mathrm{br}), 5.79(1 \mathrm{H}$, ddd, $J=17.3,10.4,7.6 \mathrm{~Hz}), 7.29-7.36$ $(5 \mathrm{H}) ;{ }^{13} \mathrm{C} \mathrm{NMR}\left(\mathrm{CDCl}_{3}, 100 \mathrm{MHz}\right) \delta 13.2,13.3,25.3,26.7,26.9,53.4,66.7,79.5,82.2$, $109.3,119.1,124.0,128.1,128.4,134.8,136.4,136.7,155.5$. Anal. Calcd for $\mathrm{C}_{20} \mathrm{H}_{27} \mathrm{NO}_{4}: \mathrm{C}, 69.54 ; \mathrm{H}, 7.88 ; \mathrm{N}, 4.05$. Found: $\mathrm{C}, 69.32 ; \mathrm{H}, 8.17 ; \mathrm{N}, 4.11$.

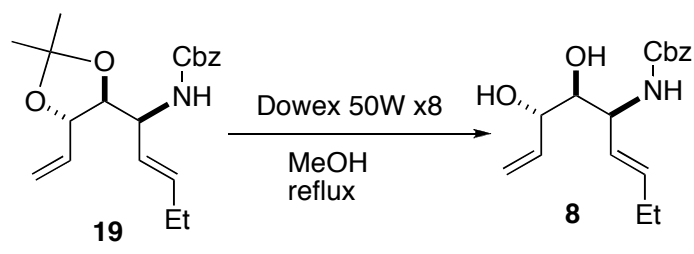

Benzyl $\{(1 S, 2 E)-1-[(1 S, 2 S)-1,2-d i h y d r o x y b u t-3-e n-1-y l]$ pent-2-en-1-yl $\}$ carbamate

8: A suspension of benzyl carbamate 19 (214 mg, $0.62 \mathrm{mmol})$ and Dowex 50W x8 (3.5 $\mathrm{ml}$ ) in $\mathrm{MeOH}\left(12.5 \mathrm{ml}\right.$ ) was vigorously stirred at reflux (oil bath temperature $70{ }^{\circ} \mathrm{C}$ ) for $26 \mathrm{~h}$. The reaction mixture was filtered and then concentrated under reduced pressure. The resultant residue was purified by silica gel chromatography (3:2 AcOEt/hexane) to afford diol 8 (173 mg, 92\%) as colorless prismatic needles. Further recrystallization from $\mathrm{Et}_{2} \mathrm{O} /$ hexane afforded an analytically pure sample: $\mathrm{mp} 67-68{ }^{\circ} \mathrm{C} ;[\alpha]_{\mathrm{D}}{ }^{15}=-5.1(c$ $\left.1.09, \mathrm{CHCl}_{3}\right)$; IR (KBr) $v_{\max } 3339,1704,1659 \mathrm{~cm}^{-1} ;{ }^{1} \mathrm{H} \mathrm{NMR}\left(\mathrm{CDCl}_{3}, 400 \mathrm{MHz}\right) \delta$ $0.99(3 \mathrm{H}, \mathrm{t}, J=7.3), 2.07(2 \mathrm{H}, \mathrm{qn}, J=7.3), 2.81(1 \mathrm{H}, \mathrm{br}), 2.99(1 \mathrm{H}, \mathrm{br}), 3.48(1 \mathrm{H}, \mathrm{t}, J=$ $5.5), 4.11(1 \mathrm{H}$, brt, $J=5.5), 4.19-4.26(1 \mathrm{H}), 5.08-5.12(2 \mathrm{H}), 5.25(1 \mathrm{H}, \mathrm{d}, J=10.5)$, $5.35(1 \mathrm{H}, \mathrm{d}, J=17.1), 5.38(1 \mathrm{H}, \mathrm{br}), 5.50(1 \mathrm{H}, \mathrm{dd}, J=15.5,6.8), 5.75(1 \mathrm{H}, \mathrm{dt}, J=15.5$, 7.3), $5.88(1 \mathrm{H}, \mathrm{ddd}, J=17.1,10.5,5.5), 7.29-7.36(5 \mathrm{H}) ;{ }^{13} \mathrm{C} \mathrm{NMR}\left(\mathrm{CDCl}_{3}, 100 \mathrm{MHz}\right)$ $\delta$ 13.2, 25.3, 54.8, 66.8, 72.6, 75.5, 117.4, 124.1, 127.97, 128.04, 128.4, 136.18, 136.22, 136.6, 156.3. Anal. Calcd for $\mathrm{C}_{17} \mathrm{H}_{23} \mathrm{NO}_{4}: \mathrm{C}, 66.86 ; \mathrm{H}, 7.59 ; \mathrm{N}, 4.59$. Found: C, $66.66 ; \mathrm{H}, 7.71 ; \mathrm{N}, 4.44$. 


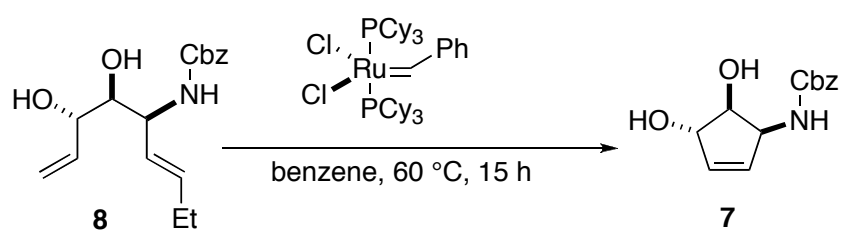

Benzyl [(1S,4S,5S)-4,5-dihydroxycyclopent-2-en-1-yl]carbamate 7: A dry Schlenk flask was charged with diol 8 (130 mg, $0.43 \mathrm{mmol})$ and benzene (43.0 ml, 0.01 M). The solution was degassed by three freeze-thaw cycles. After cooling the Schlenk flask at $-78{ }^{\circ} \mathrm{C}$, benzylidene-bis(tricyclohexylphosphine) dichlororuthenium (18 $\mathrm{mg}$, $0.02 \mathrm{mmol}$ ) was placed on the resulting solidified mixture. The Schlenk flask was evacuated and then heated at $60{ }^{\circ} \mathrm{C}$ for $15 \mathrm{~h}$. After the reaction mixture was cooled to room temperature, $\mathrm{Et}_{3} \mathrm{~N}(0.01 \mathrm{ml}, 0.09 \mathrm{mmol})$ was added. After stirring at room temperature for $24 \mathrm{~h}$, the reaction mixture was concentrated under reduced pressure. The resulting residue was purified by silica gel chromatography (4:1 AcOEt/hexane) to afford cyclopentene $7(88 \mathrm{mg}, 83 \%)$ as colorless prismatic needles. Further recrystallization from $\mathrm{MeOH} / \mathrm{AcOEt}$ afforded an analytically pure sample: mp $194{ }^{\circ} \mathrm{C}$; $[\alpha]_{\mathrm{D}}{ }^{20}=-42.1$ (c 1.15, $\left.\mathrm{CH}_{3} \mathrm{OH}\right)$; IR (KBr) $v_{\max } 3289,1692 \mathrm{~cm}^{-1} ;{ }^{1} \mathrm{H}$ NMR $\left(\mathrm{CD}_{3} \mathrm{OD}\right.$, $400 \mathrm{MHz}) \delta 3.84(1 \mathrm{H}, \mathrm{t}, J=5.4), 4.34(1 \mathrm{H}, \mathrm{br}), 4.42(1 \mathrm{H}, \mathrm{br}), 5.04-5.12(2 \mathrm{H}), 5.67$ $(1 \mathrm{H}, \mathrm{dt}, J=6.1,1.6), 5.77(1 \mathrm{H}, \mathrm{dt}, J=6.1,1.7), 7.26-7.36(5 \mathrm{H}) ;{ }^{13} \mathrm{C} \mathrm{NMR}\left(\mathrm{CD}_{3} \mathrm{OD}\right.$, $100 \mathrm{MHz}) \delta 62.9,67.5,81.3,88.0,128.9,129.0,129.5,132.7,135.0,138.3,158.6$. Anal. Calcd for $\mathrm{C}_{13} \mathrm{H}_{15} \mathrm{NO}_{4}$ : C, 62.64; H, 6.07; N, 5.62. Found: C, 62.46; H, 6.18; N, 5.44 .
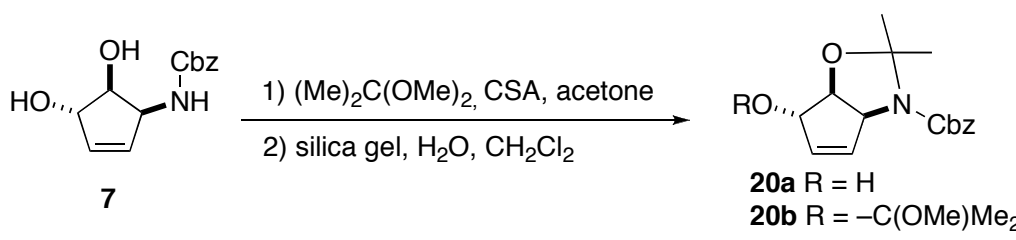

\section{Benzyl (3aS,6S,6aS)-6-hydroxy-2,2-dimethyl-6,6a-dihydro-2H-cyclopenta[d]} [1,3]oxazole-3(3aH)-carboxylate 20a: A solution of cyclopentene 7 (56 mg, 0.23 mmol), 2,2-dimethoxypropane $(0.28 \mathrm{ml}, 2.25 \mathrm{mmol})$ and CSA $(0.5 \mathrm{mg}, 0.02 \mathrm{mmol})$ in acetone $(2.5 \mathrm{ml})$ was stirred at room temperature for $6 \mathrm{~h}$. The resulting reaction mixture was poured into saturated aqueous $\mathrm{NaHCO}_{3}$ and the separated aqueous layer was extracted with $\mathrm{Et}_{2} \mathrm{O}$. The combined organic layer was washed with saturated aqueous $\mathrm{NaHCO}_{3}$, brine, dried over anhydrous $\mathrm{Na}_{2} \mathrm{SO}_{4}$, and then concentrated under 
reduced pressure. The resulting mixture of 20a and 20b (102 $\mathrm{mg})$ was dissolved in $\mathrm{CH}_{2} \mathrm{Cl}_{2}(4.2 \mathrm{ml})$, and silica gel $(1.5 \mathrm{~g})$ and $\mathrm{H}_{2} \mathrm{O}(0.3 \mathrm{~mL})$ were added. After stirring at room temperature for $7 \mathrm{~h}$, the reaction mixture was filtered through a pad of Hyflo Super $\mathrm{Cell}^{\circledR}$. Concentration under reduced pressure gave the residue, which was purified by silica gel chromatography (3:4 AcOEt/hexane) to afford the acetonide 20a $(65 \mathrm{mg}, 99 \%)$ as a colorless oil: $[\alpha]_{\mathrm{D}}{ }^{20}=+181.5\left(c 1.60, \mathrm{CHCl}_{3}\right)$; IR $(\mathrm{NaCl}) v_{\max } 3420$, $1694 \mathrm{~cm}^{-1} ;{ }^{1} \mathrm{H}$ NMR $\left(\mathrm{CD}_{3} \mathrm{OD}, 400 \mathrm{MHz}\right) \delta 1.44-1.49(6 \mathrm{H}), 4.43(1 \mathrm{H}, \mathrm{d}, J=5.4), 4.57$ $(1 \mathrm{H}, \mathrm{br}), 4.99(1 \mathrm{H}, \mathrm{brd}, J=4.1), 5.10(1 \mathrm{H}, \mathrm{d}, J=12.5), 5.16(1 \mathrm{H}, \mathrm{d}, J=12.5), 5.86(1 \mathrm{H}$, br), 5.97-6.09 (1H), 7.30-7.37 (5H); ${ }^{13} \mathrm{C} \mathrm{NMR}\left(\mathrm{CDCl}_{3}, 100 \mathrm{MHz}\right) \delta 24.5,(25.6)$, 26.7, (27.8), 65.5, (66.4), 66.7, (67.3), 80.0, (80.1), (83.2), 83.7, (95.5), 96.1, 127.7, (127.95), 128.03, (128.1), 128.5, (132.87), 132.94, (135.1), 135.4, (136.0), 136.3, 152.2, (153.1). The acetonide 20a exits as an approximate $70: 30$ mixture of rotamers on the NMR time scale. In cases where two rotamers were observed, minor carbon signals of the rotamers are listed in parentheses. Anal. Calcd for $\mathrm{C}_{16} \mathrm{H}_{19} \mathrm{NO}_{4}$ : C, 66.42; $\mathrm{H}, 6.62$; N, 4.84. Found: C, 66.14; H, 6.73; N, 4.52.

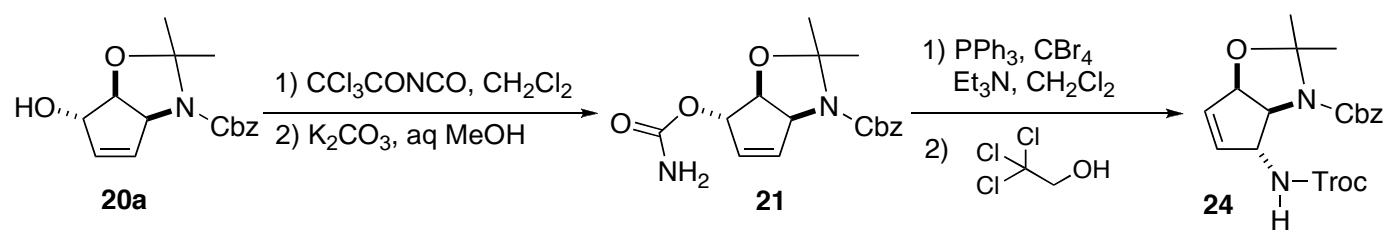

\section{Benzyl (3aS,4R,6aR)-2,2-dimethyl-4-\{[(2,2,2-trichloroethoxy)carbonyl]amino\}-} 4,6a-dihydro-2 $\mathrm{H}$-cyclopenta[ $[\boldsymbol{d}][1,3]$ oxazole-3(3aH)-carboxylate 24: To a solution of the allyl alcohol $20 \mathrm{a}(97 \mathrm{mg}, 0.33 \mathrm{mmol})$ in $\mathrm{CH}_{2} \mathrm{Cl}_{2}(4.0 \mathrm{ml})$ cooled to $0{ }^{\circ} \mathrm{C}$ was added trichloroacetyl isocyanate $(81 \mu \mathrm{l}, 0.66 \mathrm{mmol})$. After stirring at $0{ }^{\circ} \mathrm{C}$ for $30 \mathrm{~min}$, the solution was concentrated under reduced pressure. The resulting residue was dissolved in a mixture of $\mathrm{MeOH}(2.0 \mathrm{ml})$ and $1 \mathrm{M}$ aqueous potassium carbonate $(2.0$ $\mathrm{ml}$ ), and then was stirred at room temperature for $7 \mathrm{~h}$. The separated aqueous layer was extracted with $\mathrm{Et}_{2} \mathrm{O}$ (3 times) and the combined organic layer was washed with brine and dried over anhydrous $\mathrm{Na}_{2} \mathrm{SO}_{4}$. Concentration under reduced pressure provided the residue, which was purified by silica gel chromatography $3: 2$ AcOEt/hexane) to afford allyl carbamate $21(111 \mathrm{mg})$ as a colorless oil.

To a solution of the allyl carbamate $21(111 \mathrm{mg})$, triphenylphosphine (263 $\mathrm{mg}, 1.00$ mmol) and triethylamine $(417 \mu \mathrm{l}, 3.01 \mathrm{mmol})$ in $\mathrm{CH}_{2} \mathrm{Cl}_{2}(5.0 \mathrm{ml})$ cooled to $-10^{\circ} \mathrm{C}$ was 
added a solution of carbon tetrabromide $(388 \mathrm{mg}, 1.17 \mathrm{mmol})$ in $\mathrm{CH}_{2} \mathrm{Cl}_{2}(2.0 \mathrm{ml})$. The reaction mixture was stirred at $-10{ }^{\circ} \mathrm{C}$ for $40 \mathrm{~min}$, and then treated with 2,2,2-trichloroethanol (320 $\mu \mathrm{l}, 3.34 \mathrm{mmol})$. After the solution was allowed to warm to room temperature, the stirring was continued for $19 \mathrm{~h}$. The mixture was diluted with $\mathrm{Et}_{2} \mathrm{O}$ and then washed with $1 \mathrm{M}$ aqueous $\mathrm{KHSO}_{4}$, saturated aqueous $\mathrm{NaHCO}_{3}$, brine, dried over anhydrous $\mathrm{Na}_{2} \mathrm{SO}_{4}$ and then concentrated under reduced pressure. The resulting residue was purified by silica gel chromatography (1:3 AcOEt/hexane) to afford Troc-carbamate $24(147 \mathrm{mg}, 95 \%)$ as a white powdery solid: $\mathrm{mp} 95-96{ }^{\circ} \mathrm{C}$; $[\alpha]_{\mathrm{D}}{ }^{20}=-59.5\left(\right.$ c 2.90, $\left.\mathrm{CHCl}_{3}\right)$; IR $(\mathrm{KBr}) v_{\max } 3332,1742,1710 \mathrm{~cm}^{-1} ;{ }^{1} \mathrm{H} \mathrm{NMR}\left(\mathrm{CDCl}_{3}\right.$, $400 \mathrm{MHz}) \delta 1.47-1.61(6 \mathrm{H}), 4.27-4.40(2 \mathrm{H}), 4.60-4.78(2 \mathrm{H}), 5.03-5.29(4 \mathrm{H})$, $5.68-6.08(2 \mathrm{H}), 7.30-7.39(5 \mathrm{H}) ;{ }^{1} \mathrm{H}$ NMR $\left(\mathrm{CD}_{3} \mathrm{OD}, 400 \mathrm{MHz}, 328 \mathrm{~K}\right) \delta 1.49(3 \mathrm{H}, \mathrm{s})$, $1.54(3 \mathrm{H}, \mathrm{s}), 4.35(1 \mathrm{H}, \mathrm{dd}, J=6.6,2.0), 4.41(1 \mathrm{H}, \mathrm{br}), 4.69(2 \mathrm{H}, \mathrm{br}), 5.03(1 \mathrm{H}, \mathrm{br}), 5.20$ $-5.26(2 \mathrm{H}), 5.84(1 \mathrm{H}$, brd, $J=5.8), 5.95(1 \mathrm{H}, \mathrm{dt}, J=5.8,2.0), 7.27-7.38(5 \mathrm{H}) ;{ }^{13} \mathrm{C}$ NMR ( $\left.\mathrm{CD}_{3} \mathrm{OD}, 100 \mathrm{MHz}\right) \delta 25.4,(26.9), 27.6$, (28.5), (64.8), 65.5, 67.5, 67.8, (68.0), (68.5), 75.4, (75.5), (84.5), 84.7, 97.1, 98.4, 128.7, 129.0, (129.3), 129.5, (133.1), 133.9, 136.2, (137.1), 138.0, 154.3, 155.8. The Troc-carbamate 24 exits as an approximate 84 : 16 mixture of rotamers on the NMR time scale. In cases where two rotamers were observed, minor carbon signals of the rotamers are listed in parentheses. Anal. Calcd for $\mathrm{C}_{19} \mathrm{H}_{21} \mathrm{~N}_{2} \mathrm{O}_{5} \mathrm{Cl}_{3}: \mathrm{C}, 49.21 ; \mathrm{H}, 4.56 ; \mathrm{N}, 6.04$. Found: C, 49.28; H, 4.61; N, 5.69.

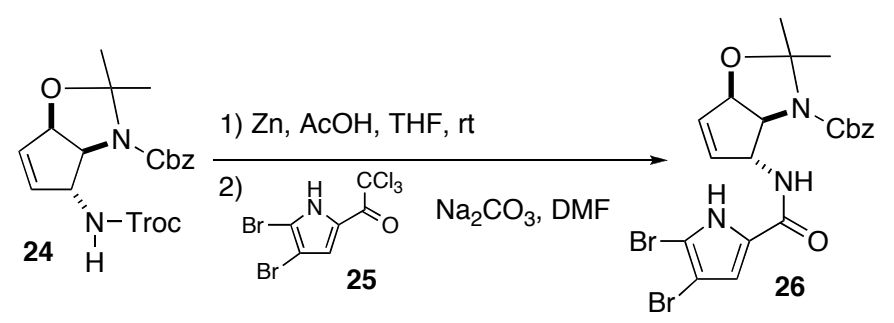

Benzyl (3aS,4R,6aR)-4-\{[(4,5-dibromo-1H-pyrrol-2-yl)carbonyl]amino\}-2,2dimethyl-4,6a-dihydro-2H-cyclopenta $[d][1,3]$ oxazole-3(3aH)-carboxylate 26 : To a solution of Troc-carbamate $24(316 \mathrm{mg}, 0.68 \mathrm{mmol})$ and AcOH $(0.28 \mathrm{ml}, 4.90 \mathrm{mmol})$ in THF (14.0 ml) was added zinc powder $(778 \mathrm{mg}, 11.9 \mathrm{mmol})$ at room temperature. After vigorous stirring for $3 \mathrm{~h}$, the suspension was diluted with AcOEt. The resulting reaction mixture was filtered through a pad of Hyflo Super Cell ${ }^{\circledR}$. The filtrate was washed with saturated aqueous $\mathrm{NaHCO}_{3}$ and dried over anhydrous $\mathrm{Na}_{2} \mathrm{SO}_{4}$. Concentration under reduced pressure provided the crude allyl amine, which was passed through a short column of silica gel (eluted with 90:10:2 $\mathrm{CHCl}_{3} / \mathrm{MeOH} / i-\mathrm{PrNH}_{2}$ ).- The 
resultant allyl amine was dissolved in $\mathrm{DMF}(2.5 \mathrm{ml})$, and then $\mathrm{Na}_{2} \mathrm{CO}_{3}(721 \mathrm{mg}, 6.80$ mmol) and 2,2,2-trichloro-1-(3,4-dibromo-1Hpyrrol-2-yl)ethanone 25 (511 mg, 1.38 mmol) was added. The reaction mixture was vigorously stirred at room temperature for $15.5 \mathrm{~h}$, and then filtered through a pad of Hyflo Super Cell ${ }^{\circledR}$. Concentration under reduced pressure provided the crude amide, which was purified by silica gel chromatography (3:7 AcOEt/hexane) to afford amide 26 (221 mg, 60\%) as a white powdery solid. Further recrystallization from $\mathrm{MeOH} / \mathrm{Et}_{2} \mathrm{O}$ afforded an analytically pure sample: $\mathrm{mp} 95-96{ }^{\circ} \mathrm{C} ;[\alpha]_{\mathrm{D}}{ }^{15}=-145.3\left(c 0.89, \mathrm{CHCl}_{3}\right)$; IR $(\mathrm{KBr}) v_{\max } 3122,1687$, $1636 \mathrm{~cm}^{-1} ;{ }^{1} \mathrm{H} \mathrm{NMR}\left(\mathrm{CD}_{3} \mathrm{OD}, 400 \mathrm{MHz}\right) \delta 1.43(3 \mathrm{H}, \mathrm{s}), 1.50(3 \mathrm{H}, \mathrm{s}), 4.31(1 \mathrm{H}, \mathrm{dd}, J=$ 6.5, 2.5), 4.74 (1H, brd, $J=12.0), 4.98(1 \mathrm{H}, \mathrm{br}), 5.04(1 \mathrm{H}, \mathrm{d}, J=12.0), 5.16$ (1H, brd, $J$ $=6.5), 5.75(1 \mathrm{H}, \mathrm{br}), 5.88(1 \mathrm{H}, \mathrm{dt}, J=5.8,2.5), 6.48(1 \mathrm{H}, \mathrm{br}), 6.95-7.25(5 \mathrm{H}) ;{ }^{13} \mathrm{C}$ $\mathrm{NMR}\left(\mathrm{CD}_{3} \mathrm{OD}, 100 \mathrm{MHz}\right) \delta 25.0,27.5,63.7,67.5,68.4,84.5,98.7,99.9,106.0,114.3$, 128.6, 128.9, 129.2, 133.0, 137.0, 137.3, 154.4, 160.7. Anal. Calcd for $\mathrm{C}_{21} \mathrm{H}_{21} \mathrm{~N}_{3} \mathrm{O}_{4} \mathrm{Br}_{2}$ : C, 46.78; H, 3.93; N, 7.79. Found: C, 46.91; H, 3.75; N, 7.49.

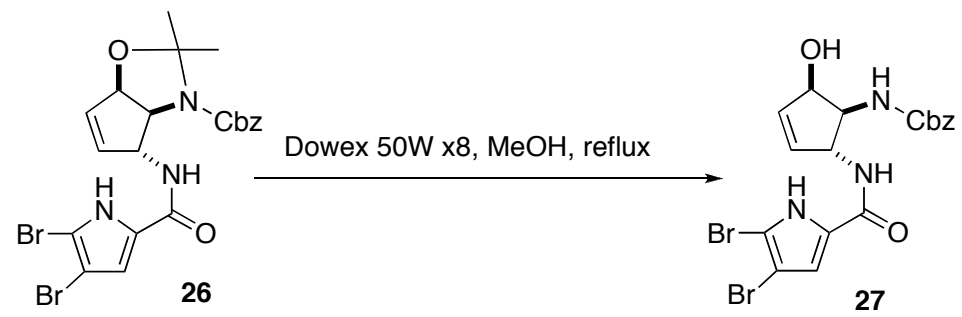

Benzyl ((1S,2R,5R)-2-\{[(4,5-dibromo-1H-pyrrol-2-yl)carbonyl]amino\}-5-hydroxy -cyclopent-3-en-1-yl)carbamate 27: A suspension of amide 26 (82 mg, $0.15 \mathrm{mmol}$ ) and Dowex 50W x8 $(1.0 \mathrm{ml})$ in $\mathrm{MeOH}(5.0 \mathrm{ml})$ was vigorously stirred at reflux (oil bath temperature $70{ }^{\circ} \mathrm{C}$ ) for $6 \mathrm{~h}$. The reaction mixture was filtered and then concentrated under reduced pressure. The resultant residue was purified by silica gel chromatography (2:1 AcOEt/hexane) to afford allyl alcohol 27 (63 $\mathrm{mg}, 83 \%)$ as an amorphous solid: $[\alpha]_{\mathrm{D}}{ }^{15}=-223.4\left(c 0.56, \mathrm{CHCl}_{3}\right)$; $\mathrm{IR}(\mathrm{KBr}) v_{\max } 3311,1704,1634$ $\mathrm{cm}^{-1} ;{ }^{1} \mathrm{H} \mathrm{NMR}\left(\mathrm{CDCl}_{3}, 400 \mathrm{MHz}\right) \delta 4.02(1 \mathrm{H}, \mathrm{t}, J=5.9), 4.58(1 \mathrm{H}$, brd, $J=2.9), 5.02$ $(1 \mathrm{H}, \mathrm{br}), 5.05(2 \mathrm{H}), 5.80-5.95(1 \mathrm{H}), 5.99-6.06(1 \mathrm{H}), 6.68-6.84(1 \mathrm{H}), 7.16-7.33$ $(5 \mathrm{H}) ;{ }^{13} \mathrm{C} \mathrm{NMR}\left(\mathrm{CDCl}_{3}, 100 \mathrm{MHz}\right) \delta 59.2,(60.1), 60.9,67.7,(68.2), 73.5,(74.0), 100.0$, 106.2, (114.5), 114.7, 128.6, 128.8, 128.9, 129.4, (134.3), 134.5, (137.4), 137.6, 138.2, 158.9, 161.9. The allyl alcohol 27 exits as an approximate $83: 17$ mixture of rotamers on the NMR time scale. In cases where two rotamers were observed, minor carbon 
signals of the rotamers are listed in parenthesis. Anal. Calcd for $\mathrm{C}_{18} \mathrm{H}_{17} \mathrm{~N}_{3} \mathrm{O}_{4} \mathrm{Br}_{2}$ : C, 43.31 ; H, 3.43; N, 8.42. Found: C, 43.65; H, 3.66; N, 8.31.

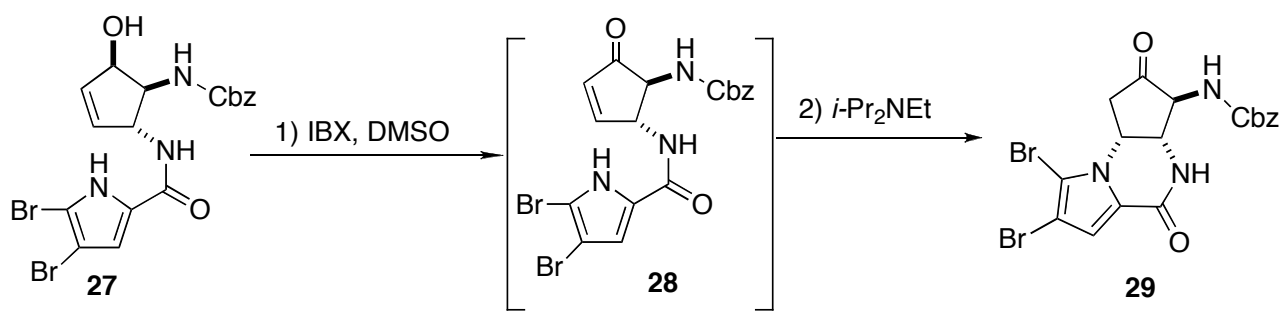

\section{Benzyl [(3S,3aS,9aR)-7,8-dibromo-2,5-dioxo-2,3,3a,4,5,9a-hexahydro-1H-}

cyclopenta[e]pyrrolo[1,2-a]pyrazin-3-yl]carbamate 29: A solution of the allyl alcohol 27 (64 mg, $0.13 \mathrm{mmol}$ ) and IBX (107 mg, $0.38 \mathrm{mmol})$ in DMSO (12.0 ml) was stirred at room temperature for $8 \mathrm{~h}$. After checking the absence of starting material and the formation of enone 28 , Hünig base $(0.16 \mathrm{ml}, 0.90 \mathrm{mmol})$ was added. After stirring at room temperature for $3 \mathrm{~h}$, the reaction mixture was diluted with saturated aqueous $\mathrm{NH}_{4} \mathrm{Cl}$. The aqueous layer was extracted with AcOEt (3 times) and the combined organic layer was washed with brine and dried over anhydrous $\mathrm{Na}_{2} \mathrm{SO}_{4}$. Concentration under reduced pressure provided the residue, which was purified by silica gel chromatography (1:1 AcOEt/hexane) to afford oxopiperazine $29(58 \mathrm{mg}, 91 \%)$ as a white powdery solid; $\mathrm{mp} 228{ }^{\circ} \mathrm{C}$ (dec.); $[\alpha]_{\mathrm{D}}{ }^{15}=-297.0\left(c 0.14, \mathrm{CHCl}_{3}\right)$; IR $(\mathrm{KBr}) v_{\max }$ 1766, 1719, $1663 \mathrm{~cm}^{-1} ;{ }^{1} \mathrm{H}$ NMR (DMSO- $\left.d_{6}, 400 \mathrm{MHz}\right) \delta 2.21(1 \mathrm{H}, \mathrm{dd}, J=18.8,9.0)$, $2.92(1 \mathrm{H}, \mathrm{dd}, J=18.8,9.0), 4.58(1 \mathrm{H}, \mathrm{brt}, J=4.0), 4.96(1 \mathrm{H}, \mathrm{q}, J=4.0), 5.10(2 \mathrm{H}, \mathrm{s})$, $5.19-5.27(1 \mathrm{H}), 6.93(1 \mathrm{H}, \mathrm{s}), 7.31-7.43(6 \mathrm{H}), 7.59(1 \mathrm{H}, \mathrm{d}, J=8.6) ;{ }^{13} \mathrm{C} \mathrm{NMR}$ $\left(\mathrm{DMSO}_{-}, 100 \mathrm{MHz}\right) \delta 38.6,48.9,53.7,62.0$, 66.1, 99.7, 107.0, 114.7, 123.8, 127.9, 128.0, 128.4, 136.6, 156.2, 157.5, 207.9. Anal. Calcd for $\mathrm{C}_{18} \mathrm{H}_{15} \mathrm{~N}_{3} \mathrm{O}_{4} \mathrm{Br}_{2}$ : C, 43.49; $\mathrm{H}$, $3.04 ; \mathrm{N}, 8.45$. Found: C, 43.21; H, 2.92; N, 8.31. 


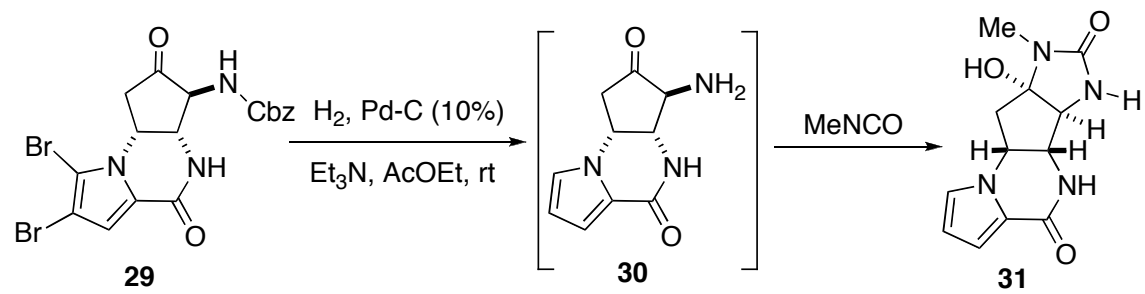

(5aS,5bS,8aS,9aR)-8a-Hydroxy-8-methyl-5,5a,5b,6,8,8a,9,9a-octahydroimidazo $\left[4^{\prime}, 5^{\prime}: 4,5\right]$ cyclopenta[1,2-e $]$ pyrrolo[1,2-a]pyrazine-4,7-dione 31: A solution of amide $29(34 \mathrm{mg}, 0.07 \mathrm{mmol})$, triethylamine $(0.06 \mathrm{ml}, 0.41 \mathrm{mmol})$ and palladium on carbon $(10 \%, 18 \mathrm{mg})$ in AcOEt $(6.8 \mathrm{ml})$ was stirred vigorously under hydrogen atmosphere for $2 \mathrm{~h}$. The resultant reaction mixture was treated with a solution of methyl isocyanate $(0.47 \mathrm{ml}, 0.68 \mathrm{mmol}, 1.47 \mathrm{M}$ solution of THF). After being stirred at room temperature for $5 \mathrm{~h}$, the reaction mixture was filtered on Hyflo Super Cell ${ }^{\circledR}$, and then concentrated. Purification by silica gel chromatography afforded debromoagelastatin 31 (14 mg, 78\%) as a white solid; mp 242.5-244 ${ }^{\circ} \mathrm{C}$; $[\alpha]_{\mathrm{D}}{ }^{15}=-69.1\left(c 0.45, \mathrm{CH}_{3} \mathrm{OH}\right)$ (lit. $^{4}[\alpha]_{\mathrm{D}}{ }^{20}=-68.4, c 0.5, \mathrm{CH}_{3} \mathrm{OH}$; lit. $^{3}[\alpha]_{\mathrm{D}}=-64.8, c 0.48, \mathrm{CH}_{3} \mathrm{OH}$; lit. $^{2}[\alpha]_{\mathrm{D}}{ }^{20}=$ -66.2, $c$ 0.21, $\left.\mathrm{CH}_{3} \mathrm{OH}\right)$; IR (KBr) $v_{\max } 3280,2940,1645,1552 \mathrm{~cm}^{-1} ;{ }^{1} \mathrm{H} \mathrm{NMR}\left(\mathrm{CD}_{3} \mathrm{OD}\right.$, $400 \mathrm{MHz}) \delta 2.27(1 \mathrm{H}, \mathrm{dd}, J=13.2,10.3), 2.62(1 \mathrm{H}, \mathrm{dd}, J=13.2,6.4), 2.79(3 \mathrm{H}, \mathrm{s})$, $3.81(1 \mathrm{H}, \mathrm{d}, J=1.0), 4.00(1 \mathrm{H}, \mathrm{dd}, J=5.4,1.0), 4.62-4.68(1 \mathrm{H}), 6.22(1 \mathrm{H}, \mathrm{dd}, J=3.9$, 2.6) $6.88(1 \mathrm{H}, \mathrm{dd}, J=3.9,1.6), 7.03(1 \mathrm{H}, \mathrm{dd}, J=2.6,1.6) ;{ }^{13} \mathrm{C} \mathrm{NMR}\left(\mathrm{CD}_{3} \mathrm{OD}, 100\right.$ $\mathrm{MHz}) \delta$ 24.2, 41.6, 55.6, 62.8, 67.9, 95.8, 111.1, 115.4, 122.8, 125.7, 161.3, 162.0. HRMS (ESI): $m / z$ calcd for $\mathrm{C}_{12} \mathrm{H}_{13} \mathrm{~N}_{4} \mathrm{O}_{3}(\mathrm{M}-\mathrm{H})^{-} 261.0988$, found 261.0992.

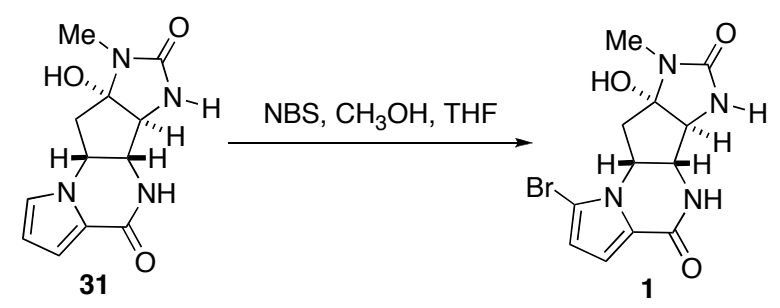

(-)-Agelastatin A (1): To a solution of debromoagelastatin 31 (7 mg, $0.027 \mathrm{mmol})$ in a mixture of $\mathrm{MeOH}(1.0 \mathrm{ml})$ and THF $(2.0 \mathrm{ml})$ cooled to $0{ }^{\circ} \mathrm{C}$ was added NBS $(4 \mathrm{mg}$, $0.24 \mathrm{mmol}$ ), and the cooling bath was removed. After stirring at room temperature for $6 \mathrm{~h}$, the solution was concentrated under reduced pressure. The crude residue was purified by column chromatography on silica gel eluting with $\mathrm{CH}_{2} \mathrm{Cl}_{2} / \mathrm{MeOH}$ (9:1) to afford (-)-agelastatin $\mathrm{A}(1)(7 \mathrm{mg}, 77 \%) ; \mathrm{mp} 193{ }^{\circ} \mathrm{C}$ (dec.); $[\alpha]_{\mathrm{D}}{ }^{14}=-83.8$ (c 0.21 , 
$\left.\mathrm{CH}_{3} \mathrm{OH}\right)\left(\right.$ lit. $^{4}[\alpha]_{\mathrm{D}}{ }^{20}=-65.5, c 0.5, \mathrm{CH}_{3} \mathrm{OH} ;$ lit. $^{3}[\alpha]_{\mathrm{D}}=-84.2, c 1, \mathrm{CH}_{3} \mathrm{OH}$; lit. $^{2}[\alpha]_{\mathrm{D}}{ }^{20}$ $=-62.2, c 0.18, \mathrm{CH}_{3} \mathrm{OH}$; lit. $\left.{ }^{5}[\alpha]_{\mathrm{D}}=-59.3, c 0.13, \mathrm{CH}_{3} \mathrm{OH}\right) ; \mathrm{IR}(\mathrm{KBr}) v_{\max } 3284,2922$, 1672, 1644, 1553, $1423 \mathrm{~cm}^{-1} ;{ }^{1} \mathrm{H} \mathrm{NMR}\left(\mathrm{CD}_{3} \mathrm{OD}, 400 \mathrm{MHz}\right) \delta 2.09(1 \mathrm{H}, \mathrm{t}, J=12.5 \mathrm{~Hz})$, $2.64(1 \mathrm{H}, \mathrm{dd}, J=12.5,6.2 \mathrm{~Hz}), 2.80(3 \mathrm{H}, \mathrm{s}), 3.88(1 \mathrm{H}, \mathrm{s}), 4.08(1 \mathrm{H}, \mathrm{d}, J=5.6 \mathrm{~Hz}), 4.59$ $(1 \mathrm{H}$, quin, $J=12.5,6.2,5.6 \mathrm{~Hz}), 6.32(1 \mathrm{H}, \mathrm{d}, J=4.0 \mathrm{~Hz}), 6.90(1 \mathrm{H}, \mathrm{d}, J=4.0 \mathrm{~Hz}) ;{ }^{13} \mathrm{C}$ $\mathrm{NMR}\left(\mathrm{CD}_{3} \mathrm{OD}, 100 \mathrm{MHz}\right) \delta$ 24.2, 40.0, 54.4, 62.2, 67.4, 95.7, 107.3, 113.8, 116.0, 124.1, 161.1, 161.4. HRMS (ESI): $m / z$ calcd for $\mathrm{C}_{12} \mathrm{H}_{12} \mathrm{~N}_{4} \mathrm{O}_{3}{ }^{79} \mathrm{Br}(\mathrm{M}-\mathrm{H})^{-} 339.0093$, found 339.0092 . 


\section{References}

(1) Stien, D.; Anderson, G. T.; Chase, C. E.; Koh, Y.; Weinreb, S. M. J. Am. Chem. Soc. 1999, 121, 9574.

(2) Davis, F. A.; Deng, J. Org. Lett. 2005, 7, 621.

(3) Domostoj, M.; Irving, E.; Scheinmann, F.; Hale, K. J. Org. Lett. 2004, 6, 2615.

(4) Feldman, K. S.; Saunders, J. C. J. Org. Chem. 2002, 67, 7096.

(5) Hong, T. W.; Jimenez, D. R.; Molinski, T. F. J. Nat. Prod. 1991, 61, 158. 


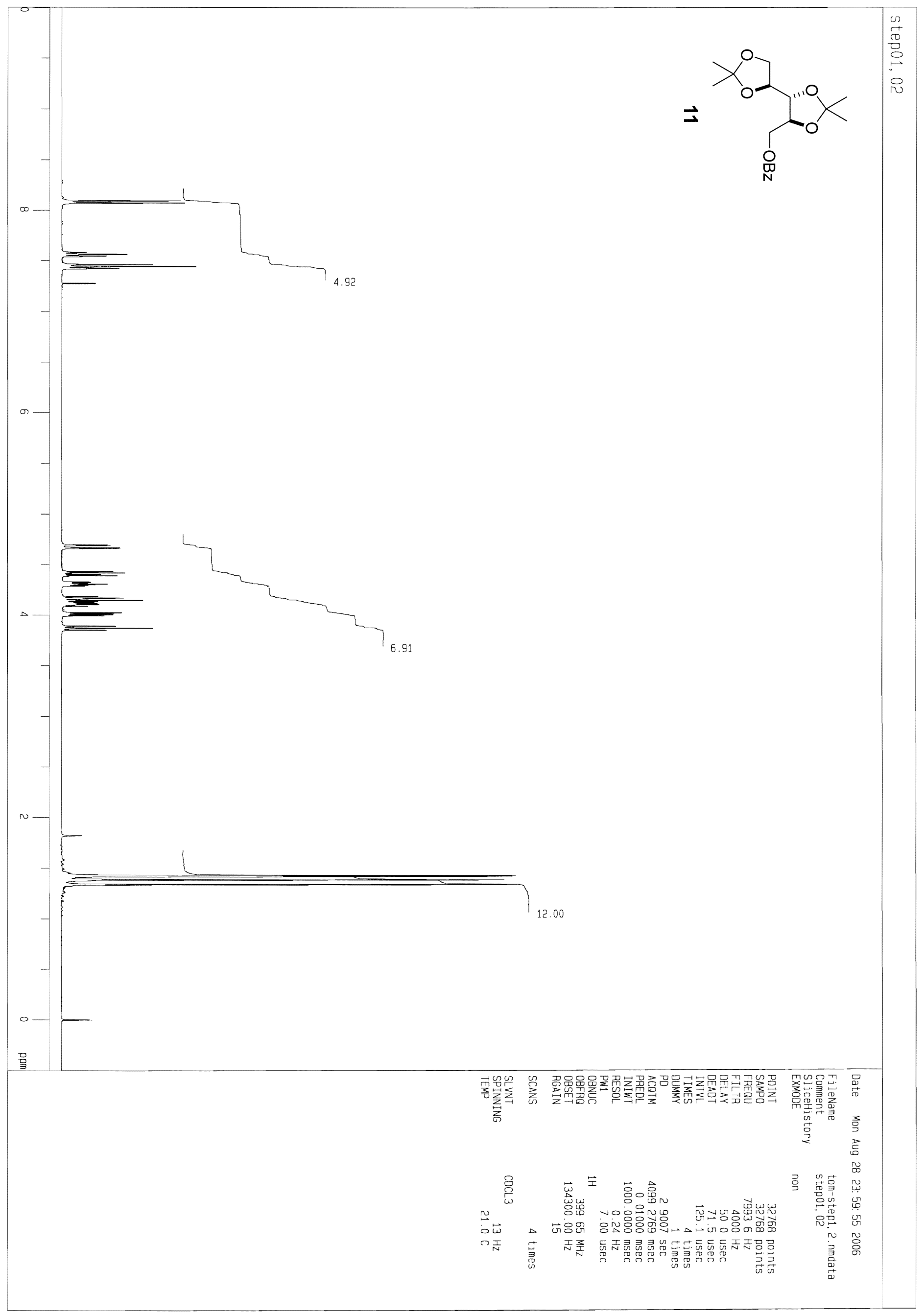

17 


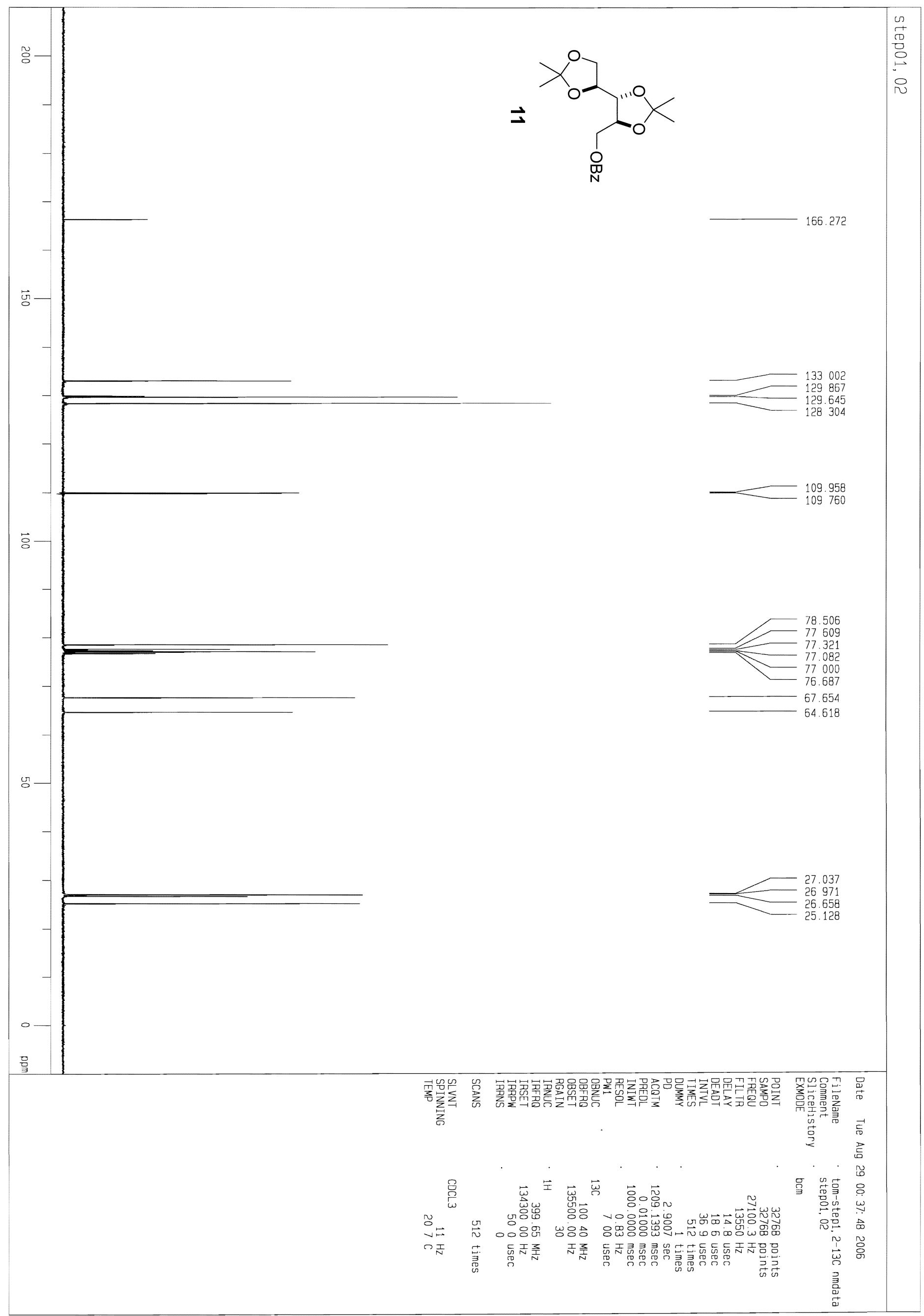




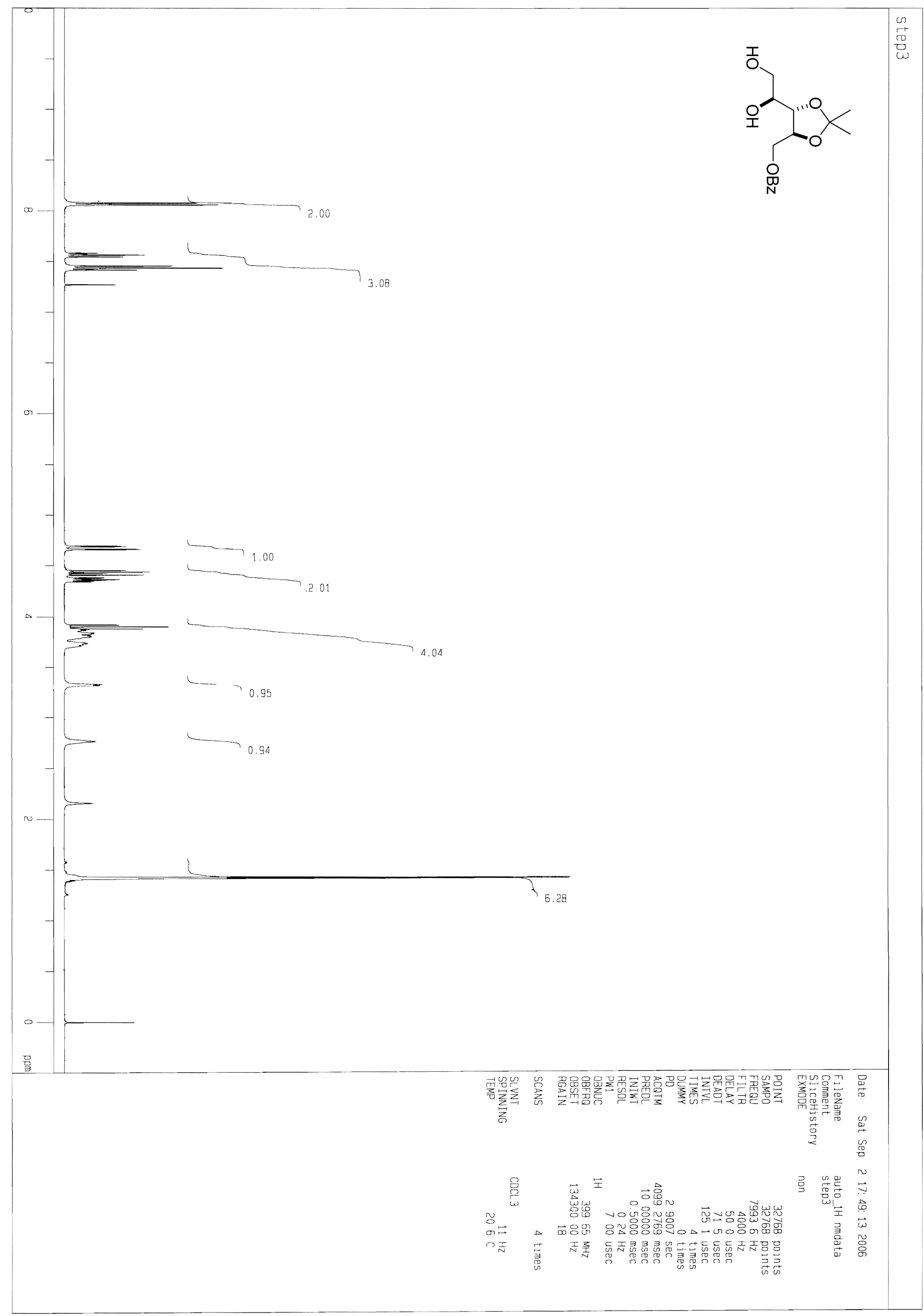




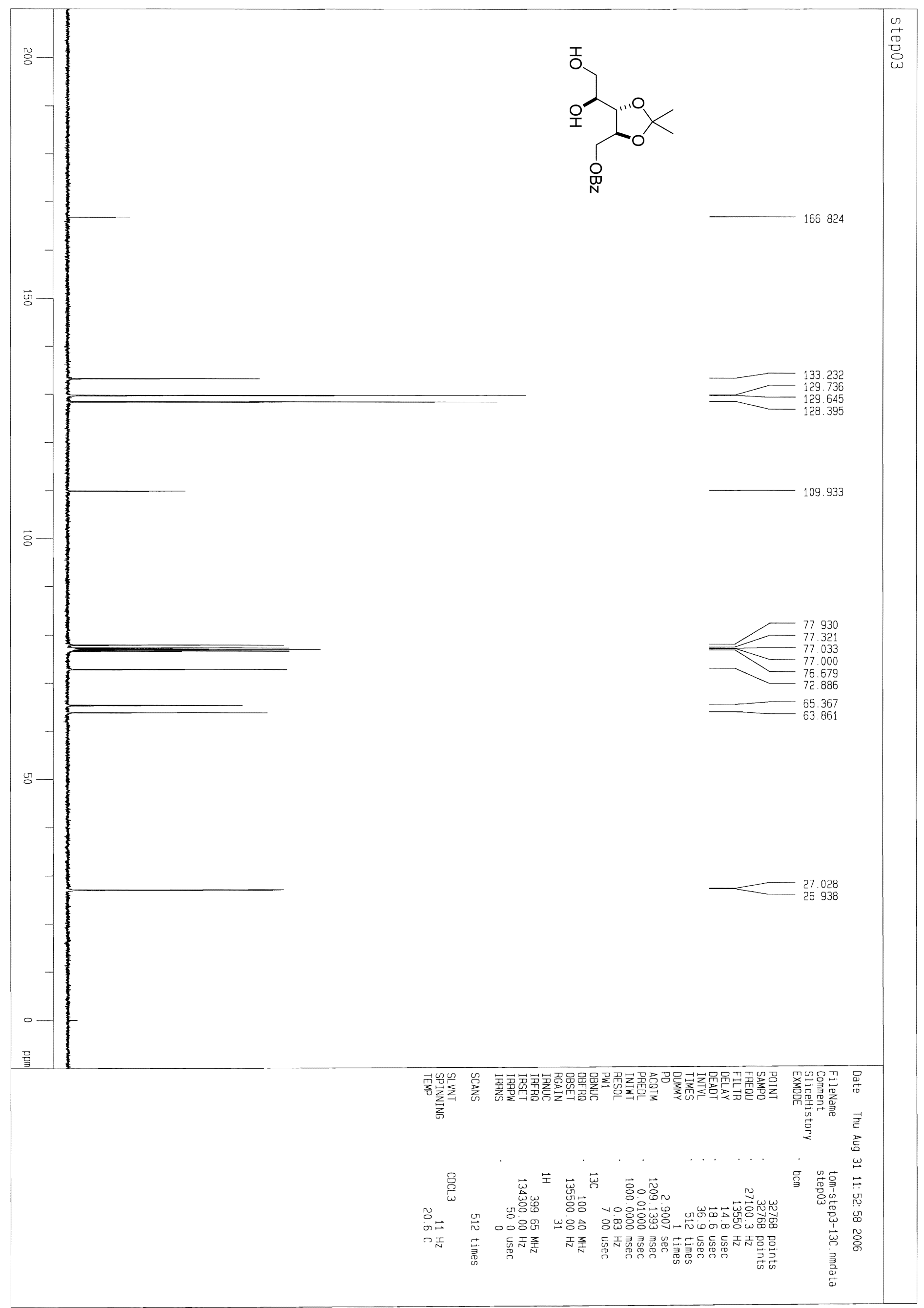




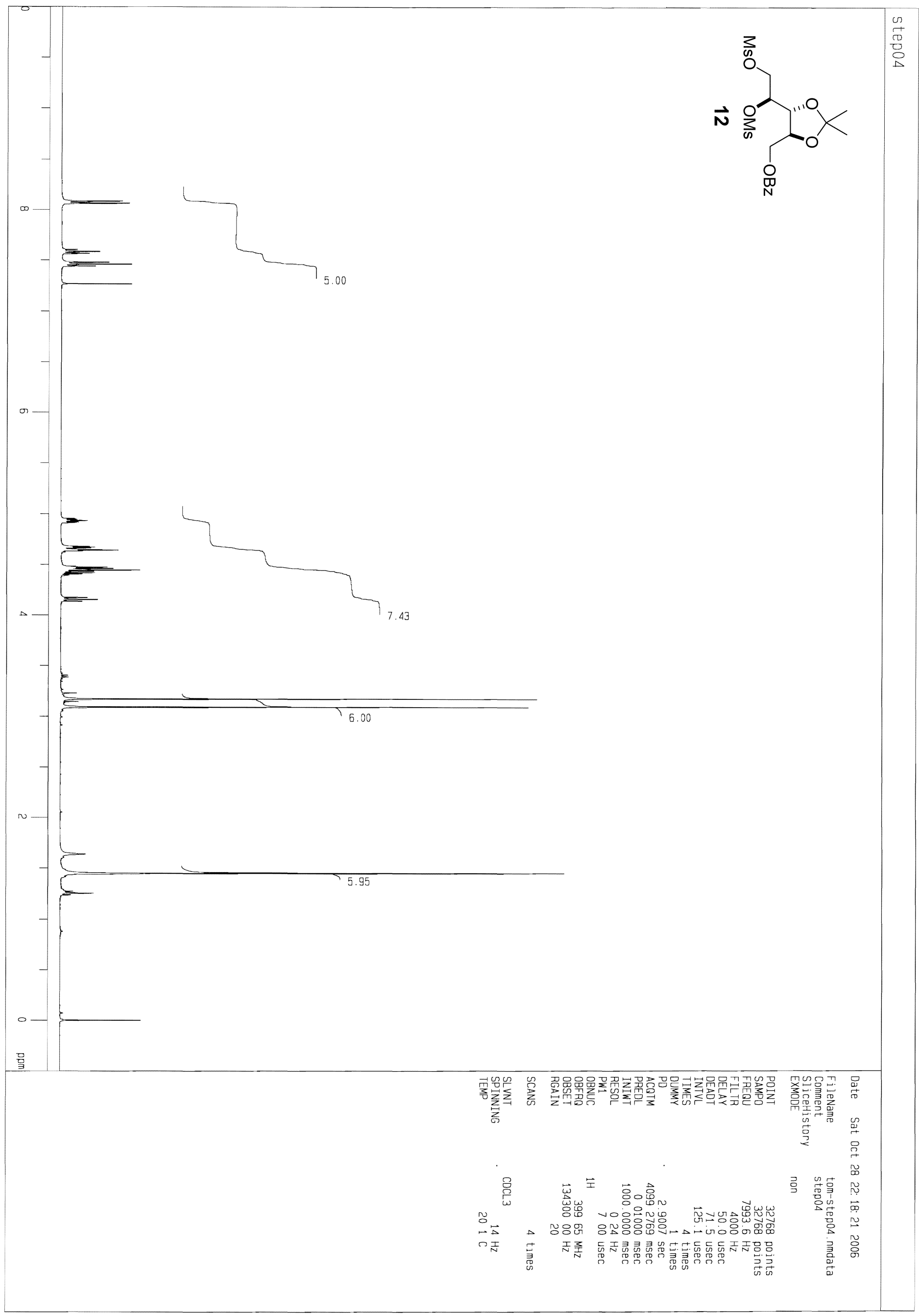

21 


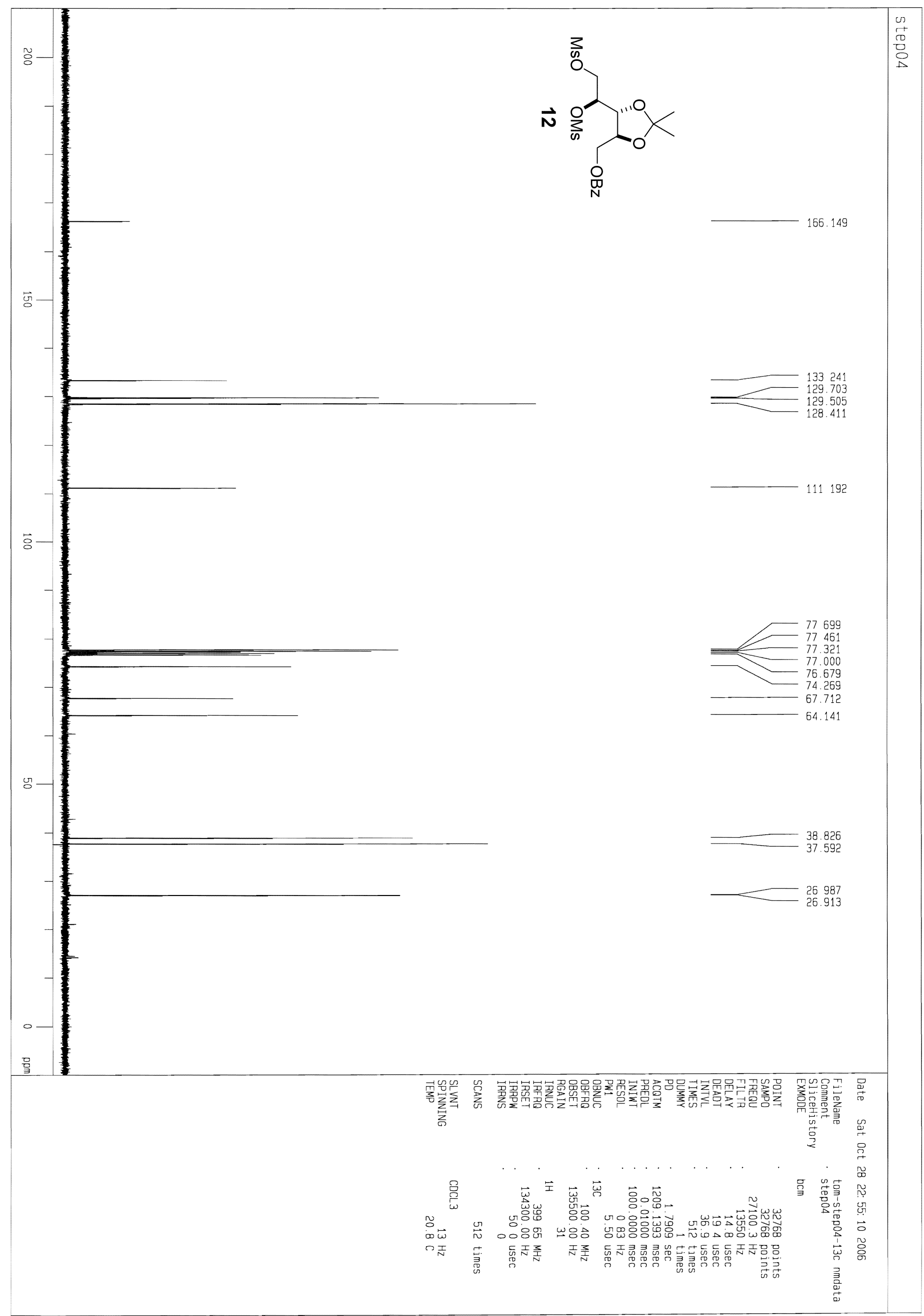




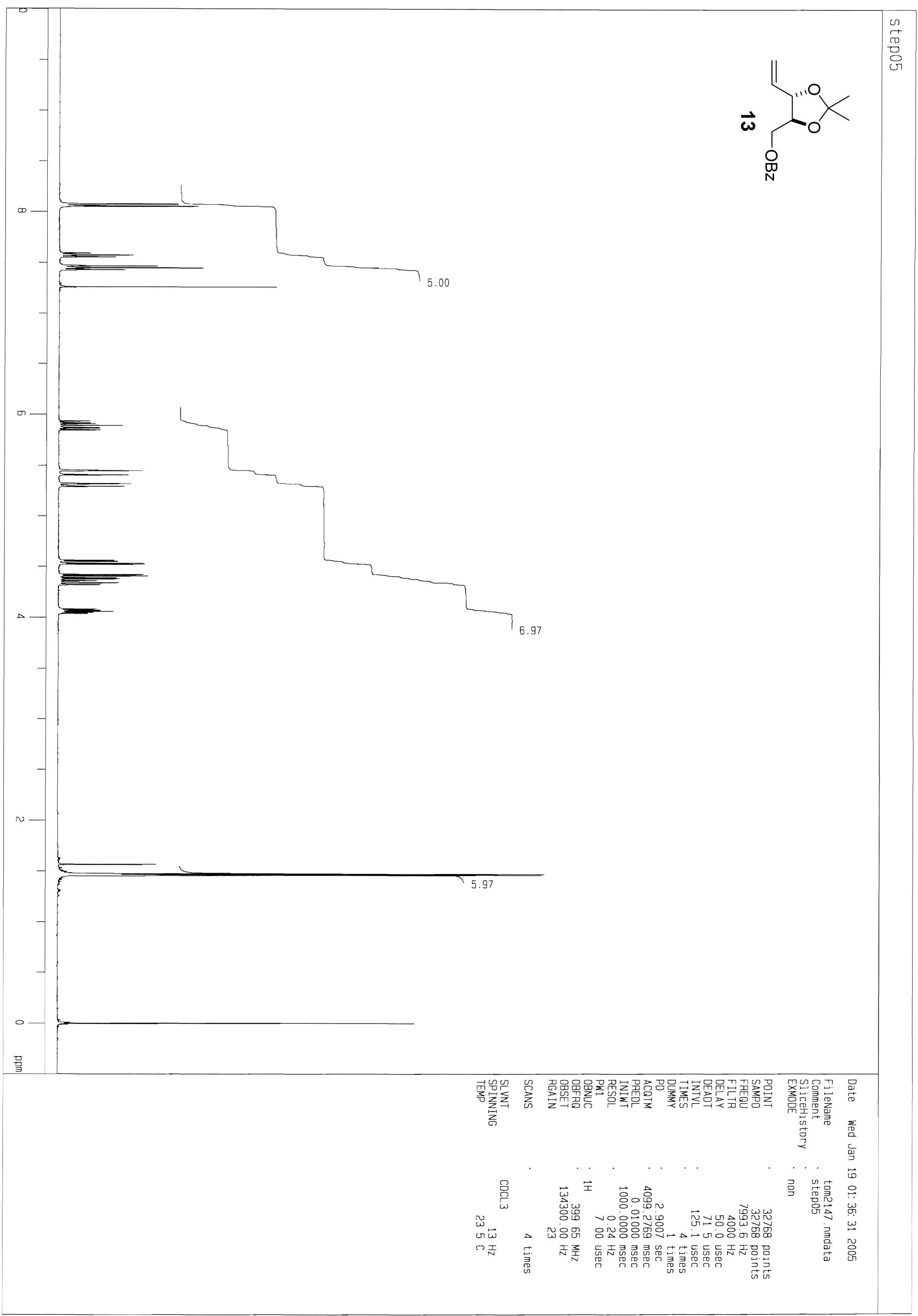




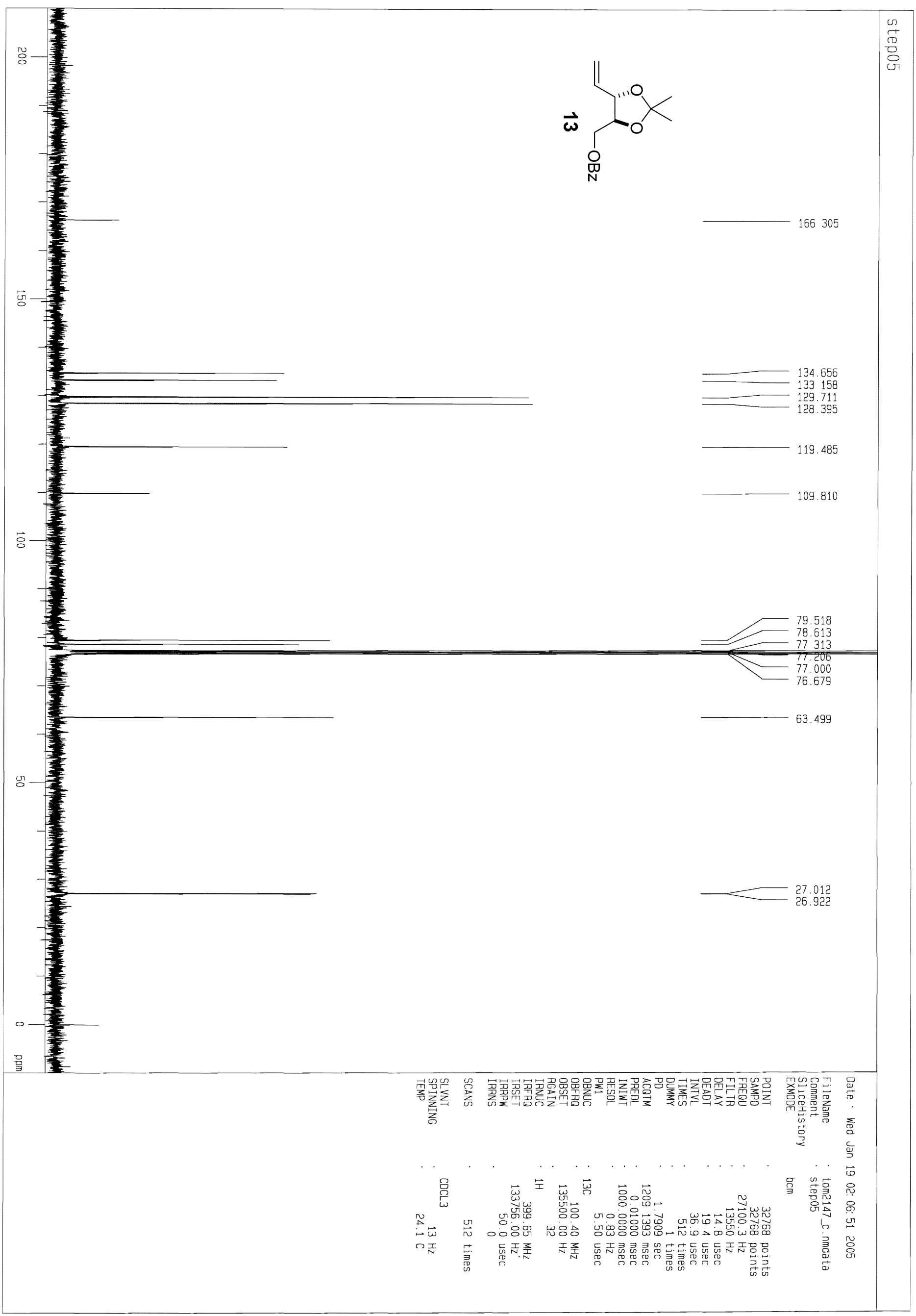




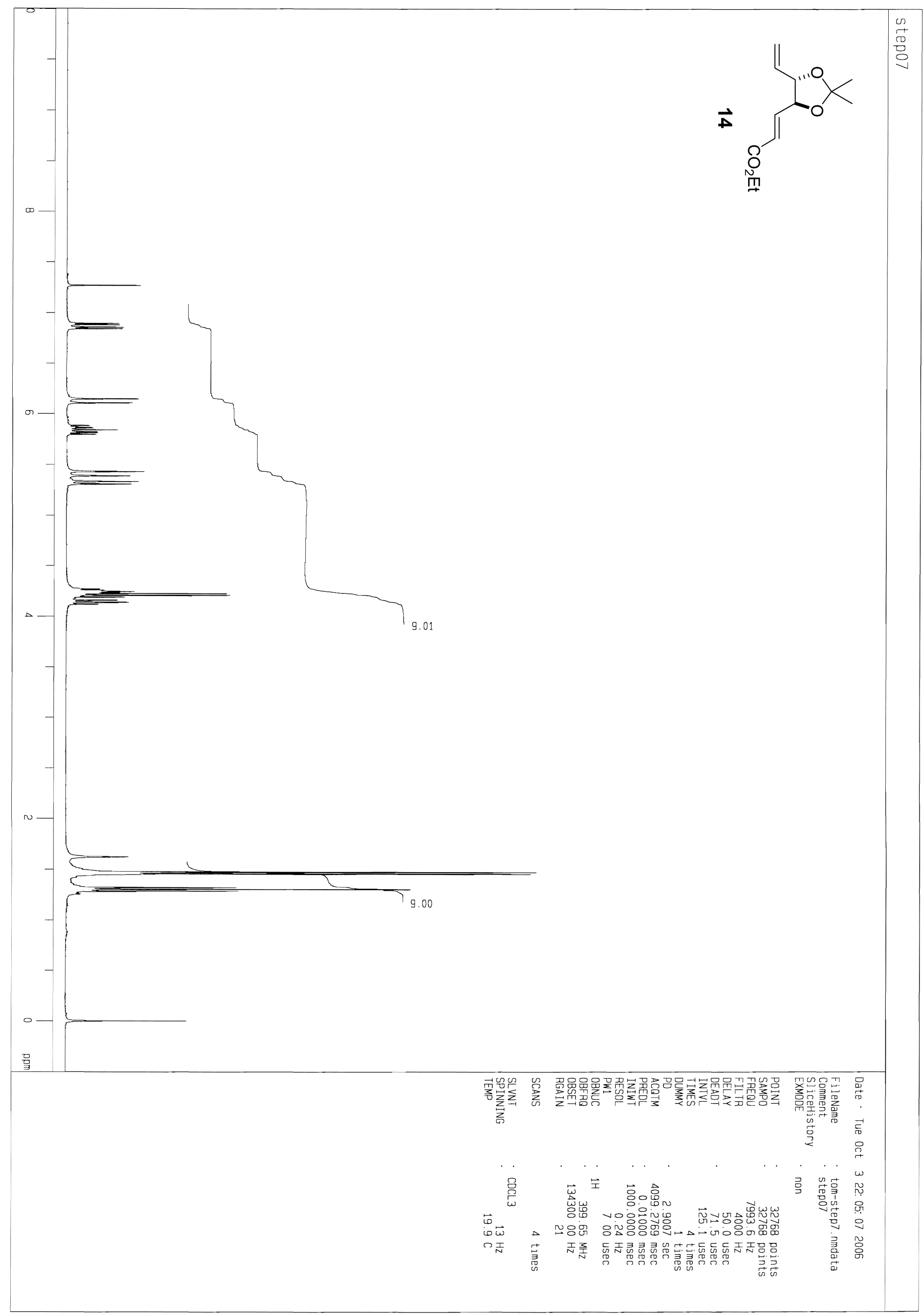




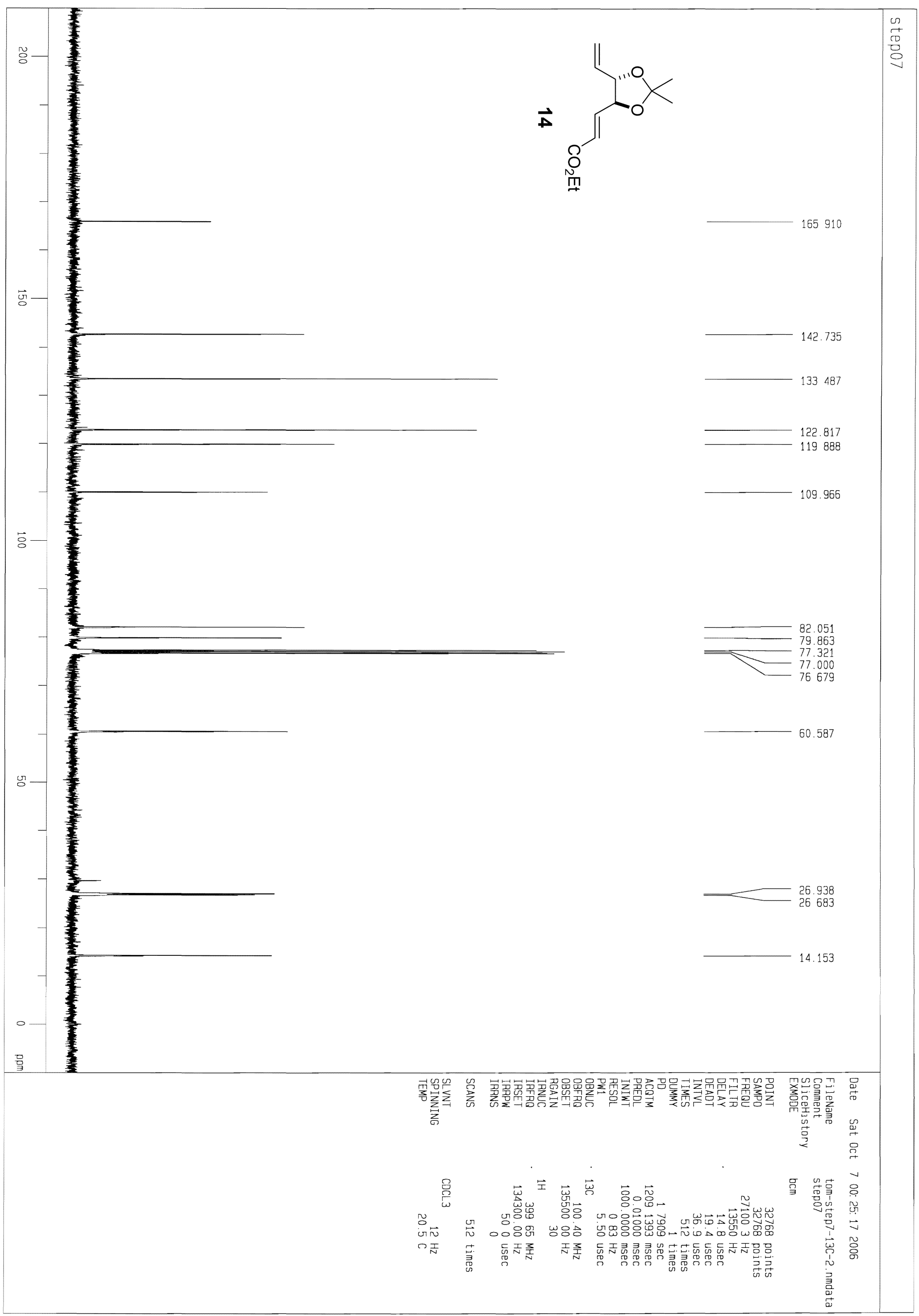




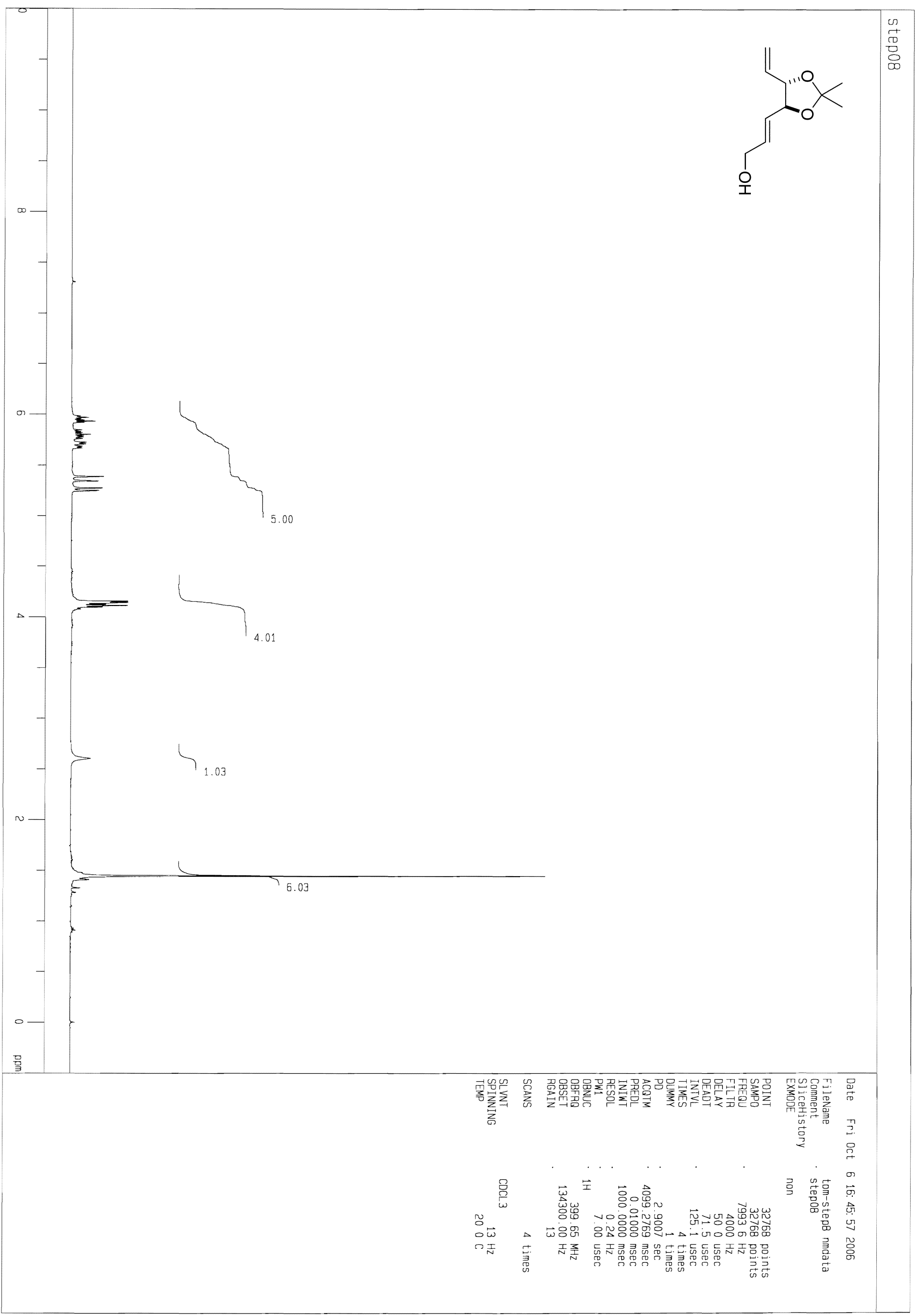




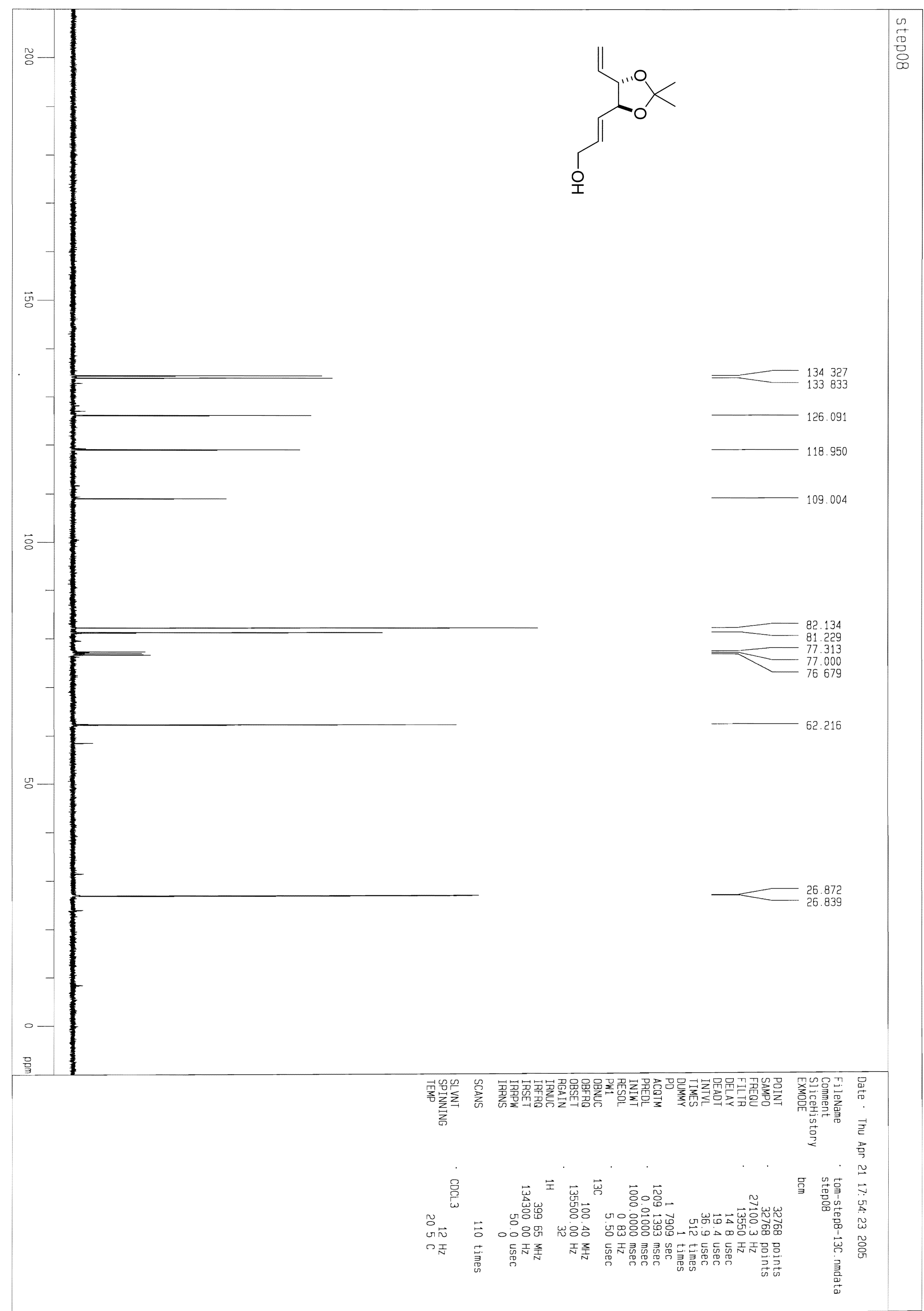




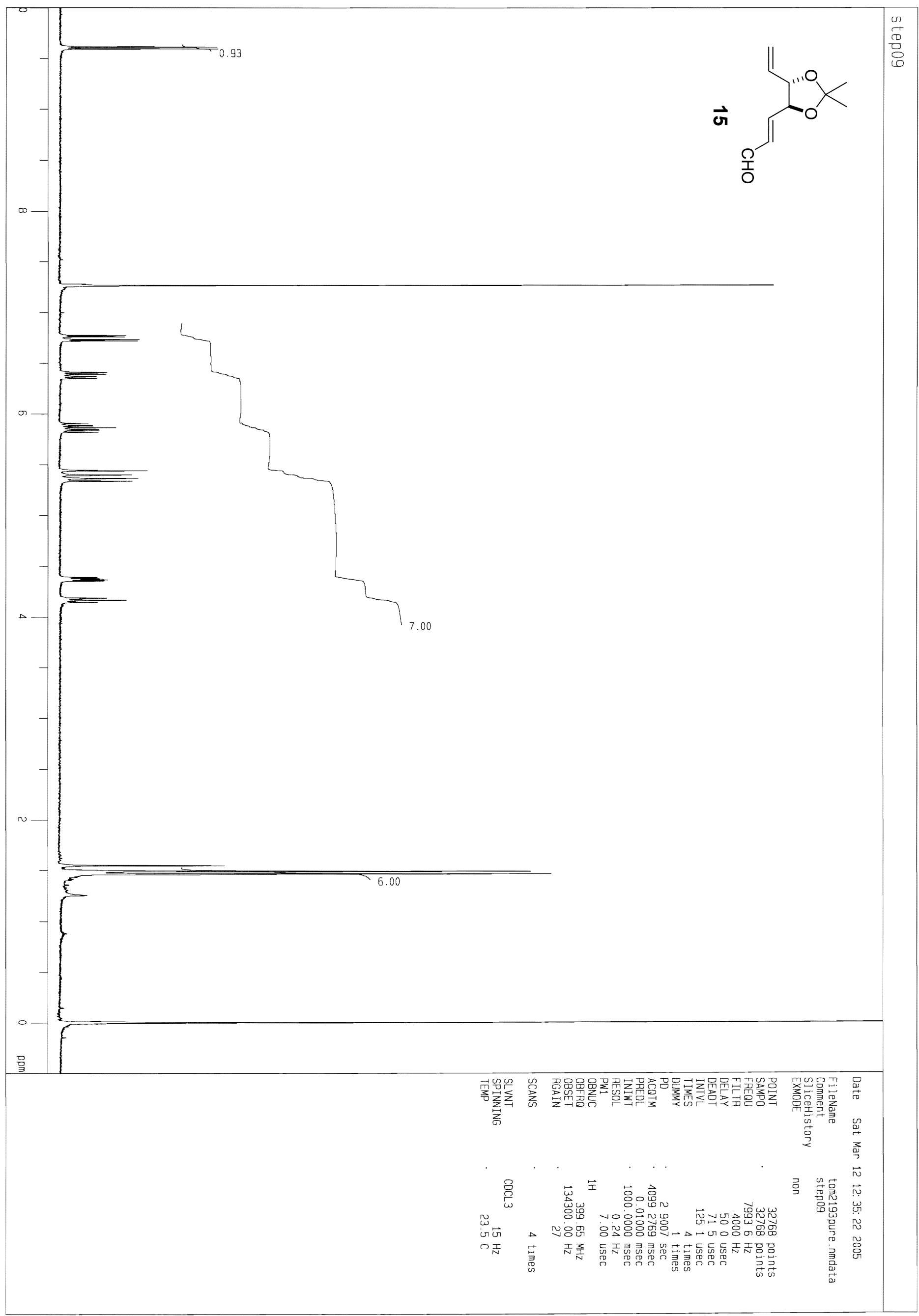




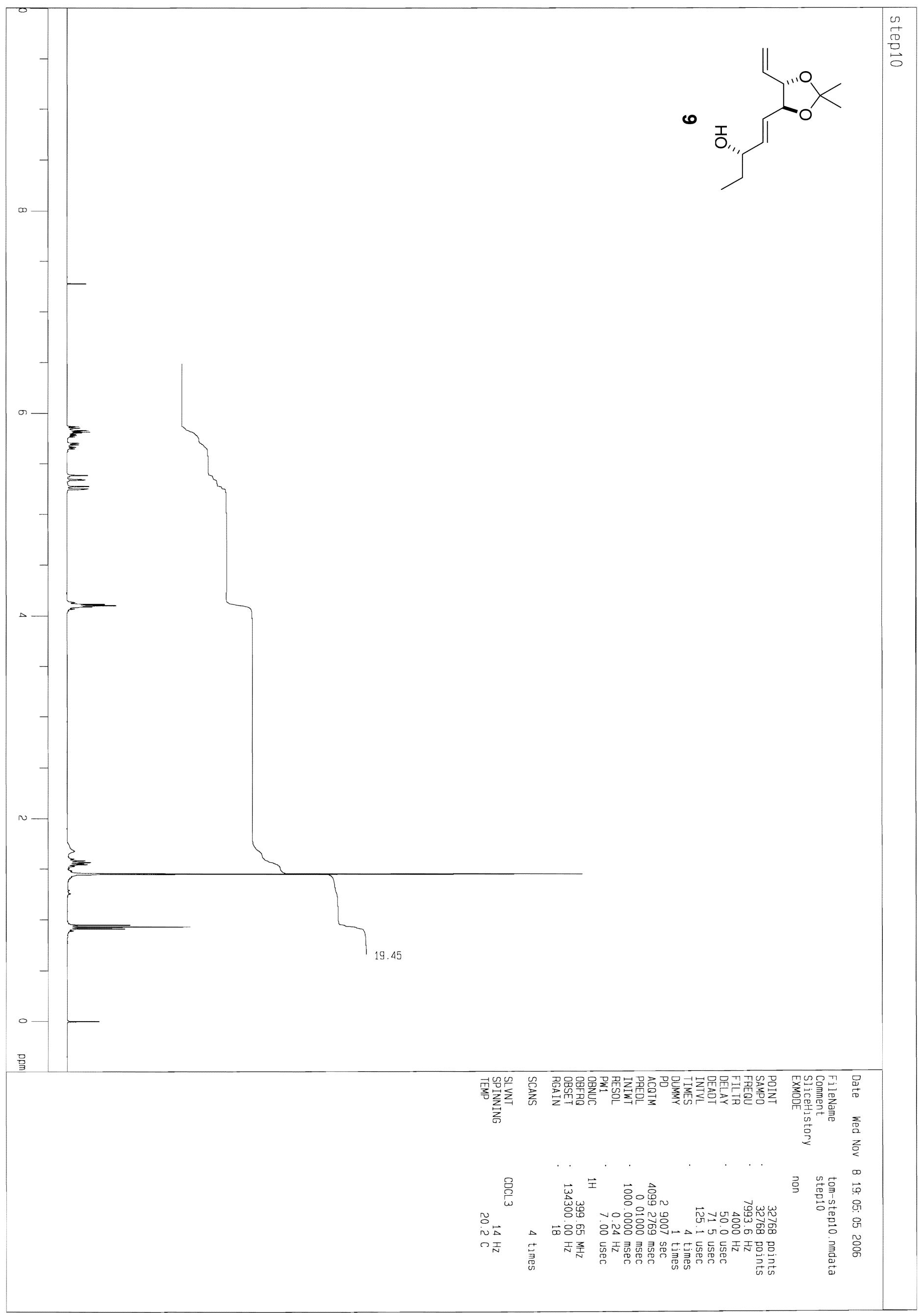




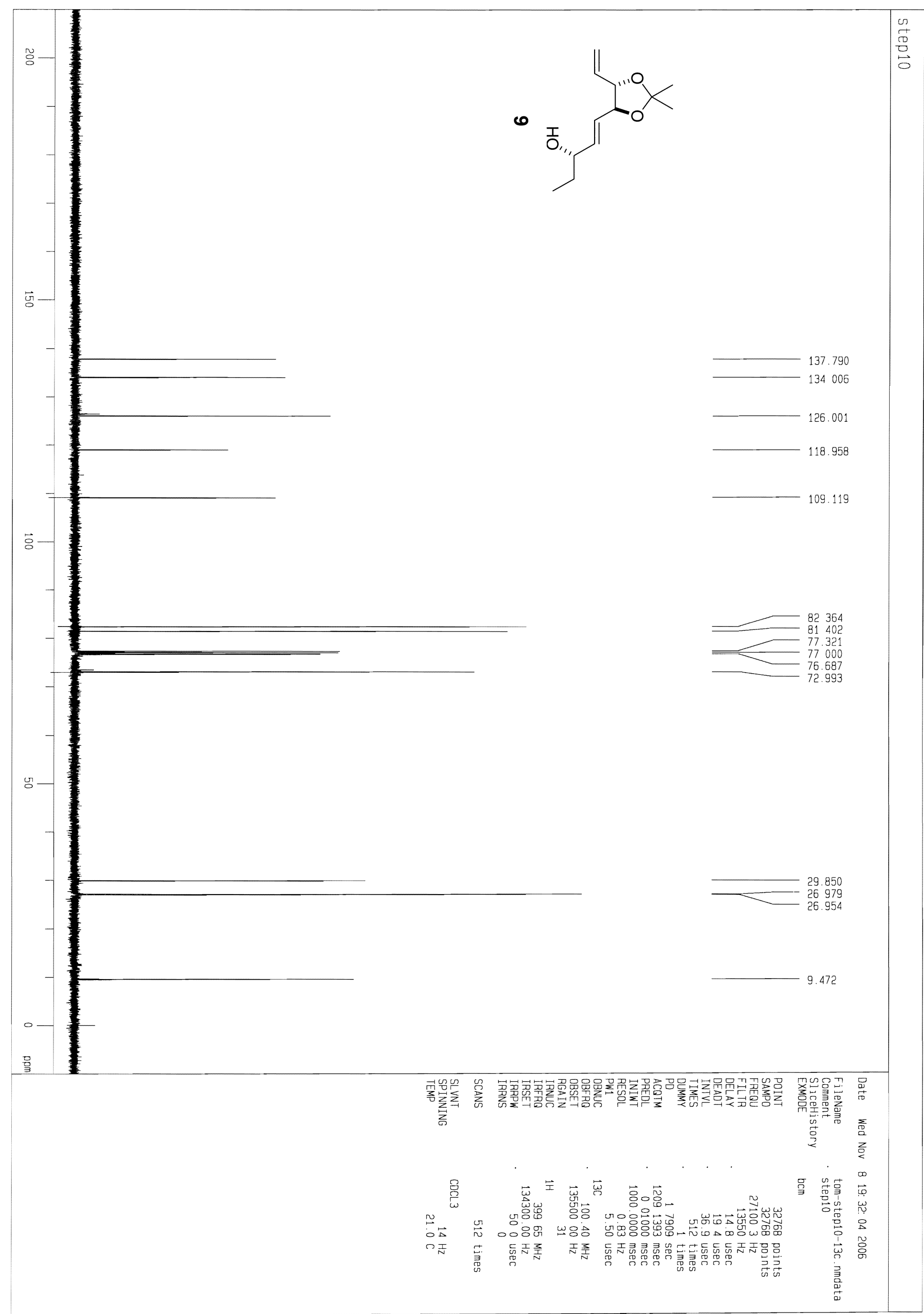




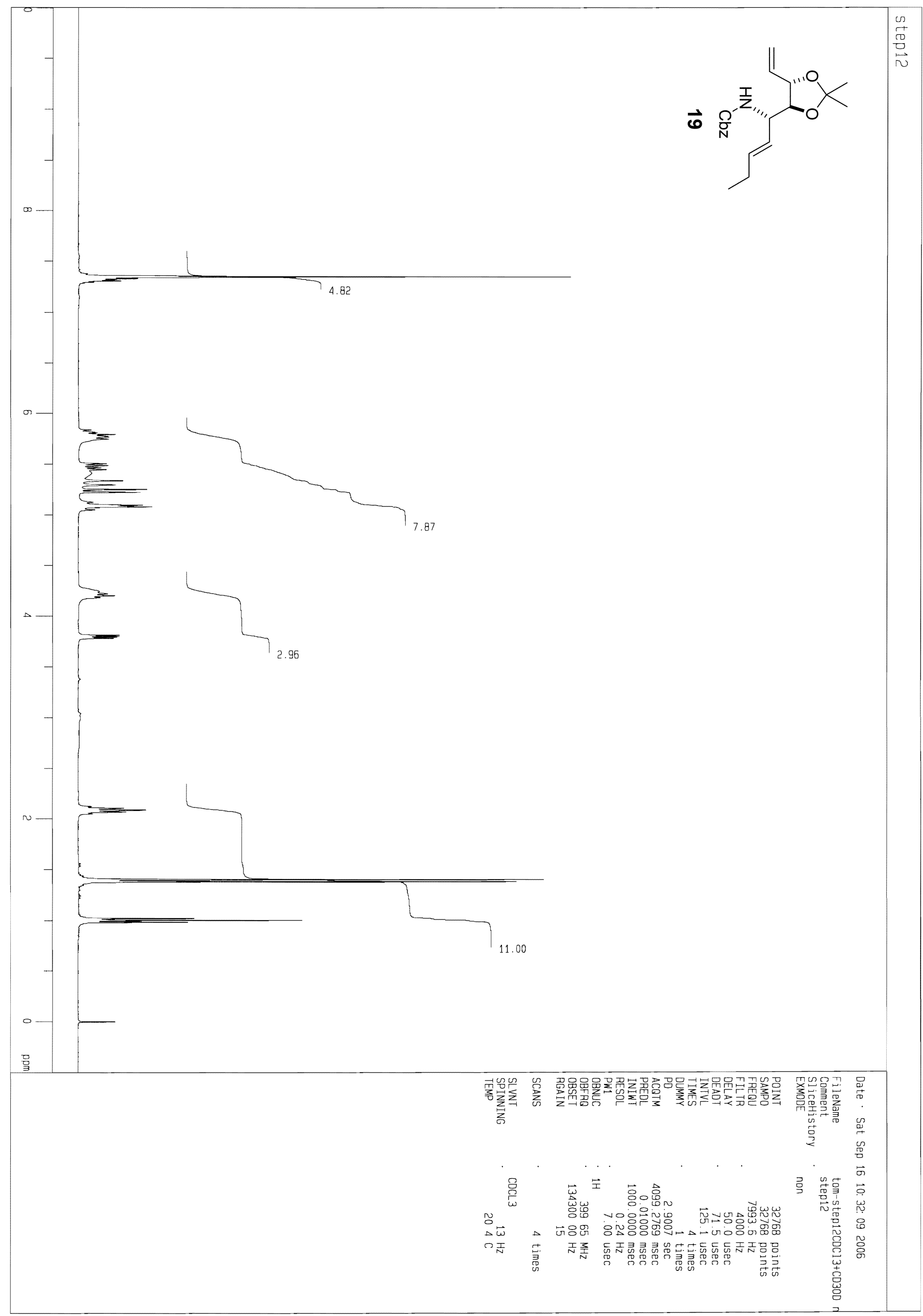




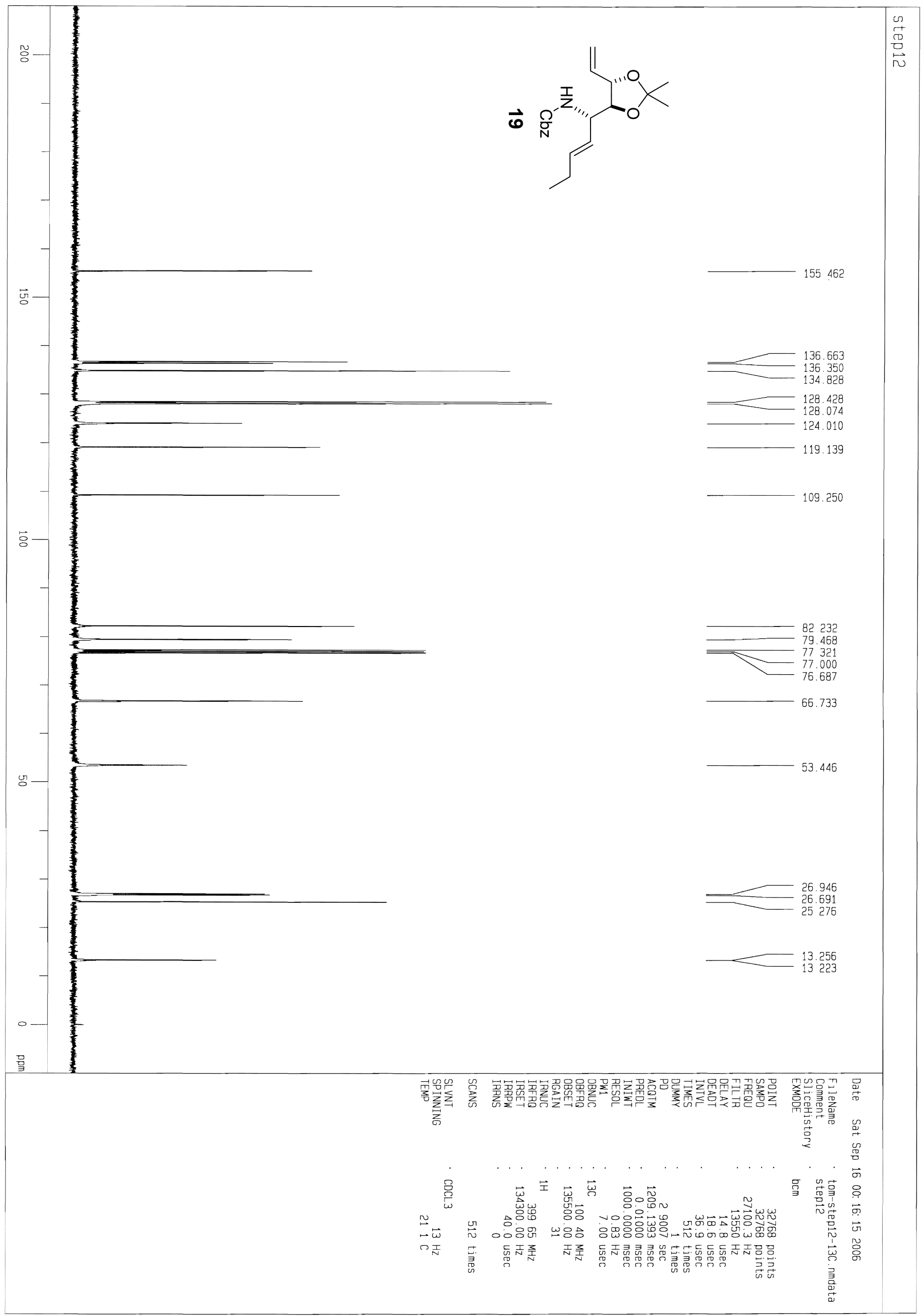

33 


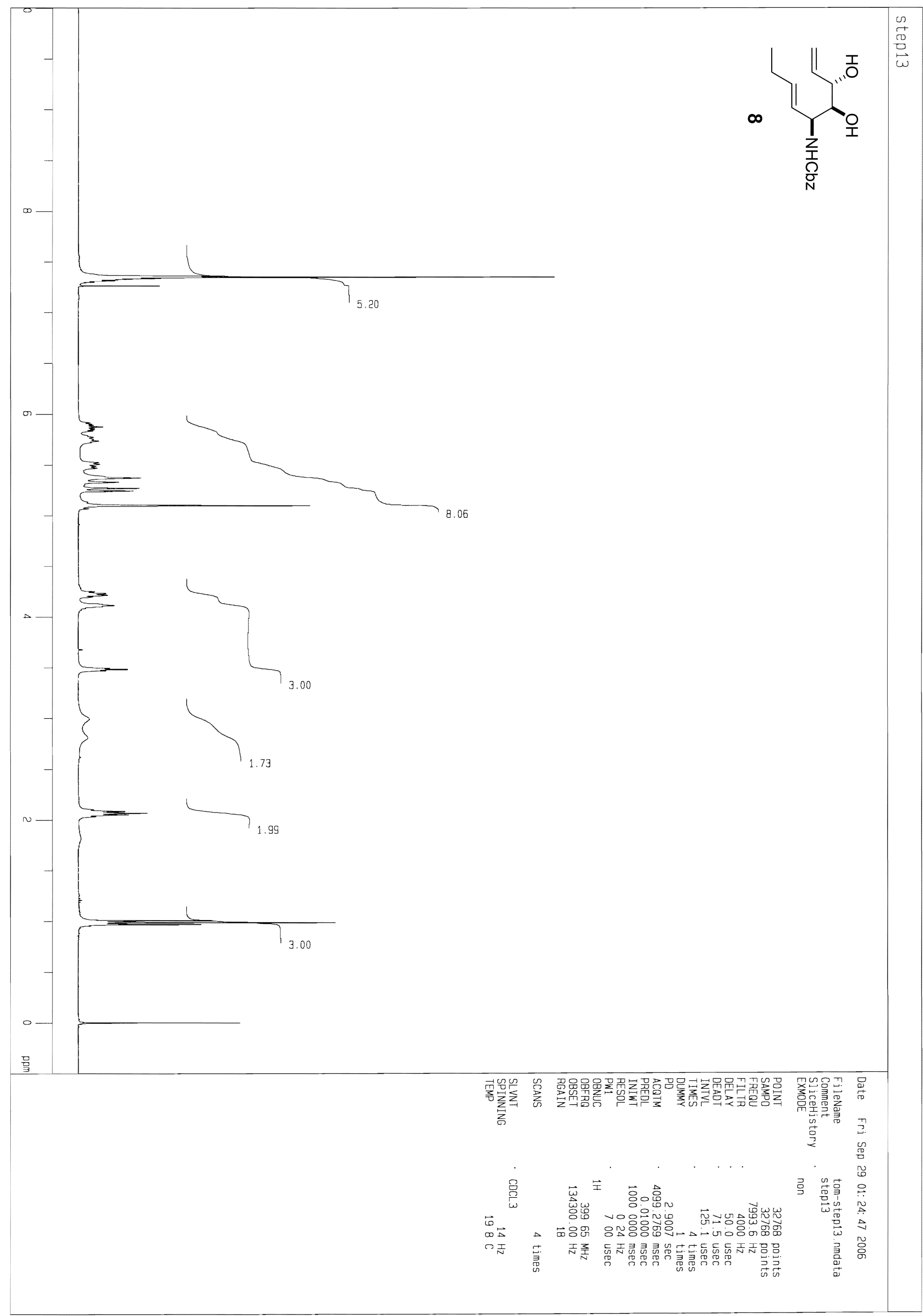




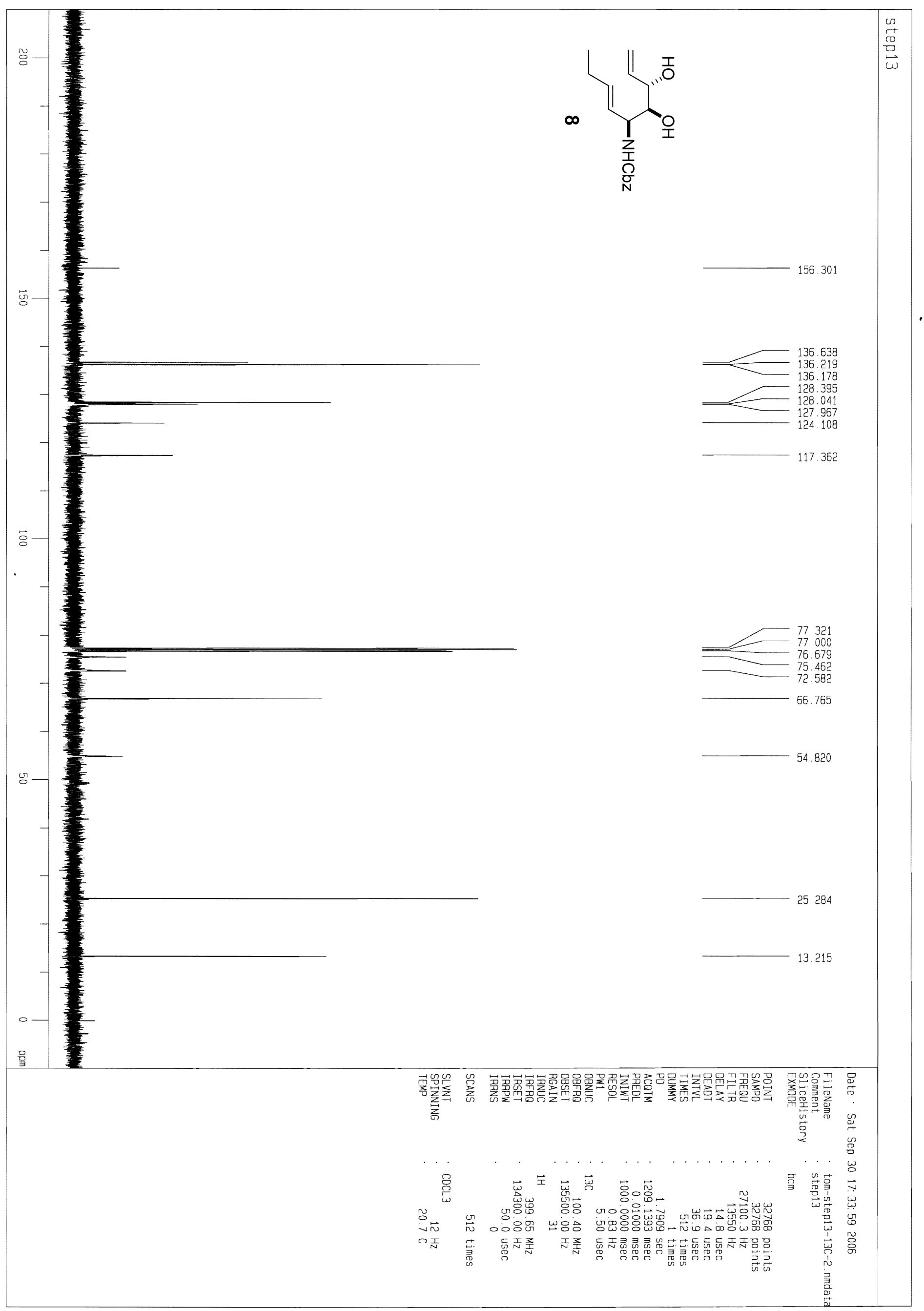




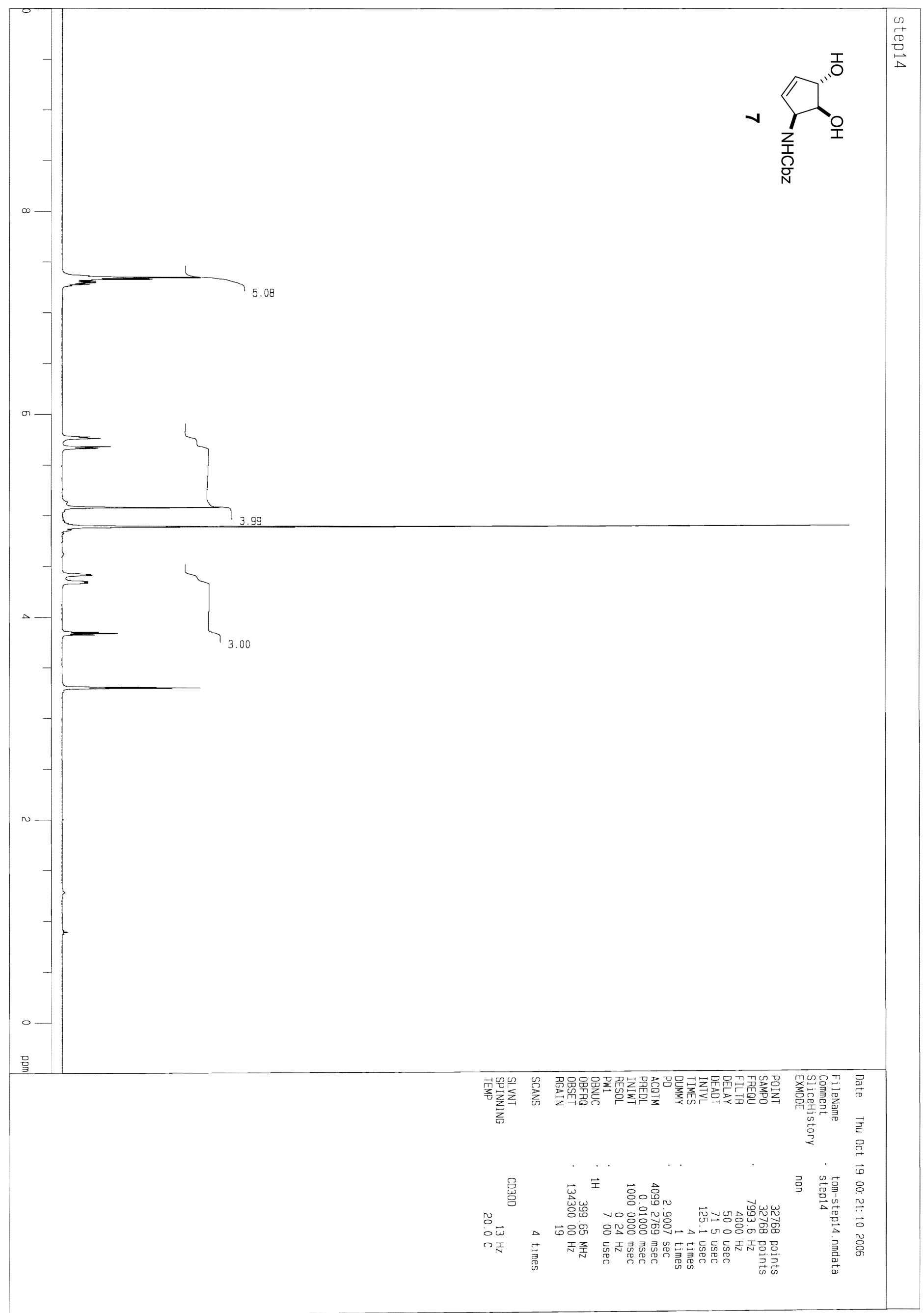




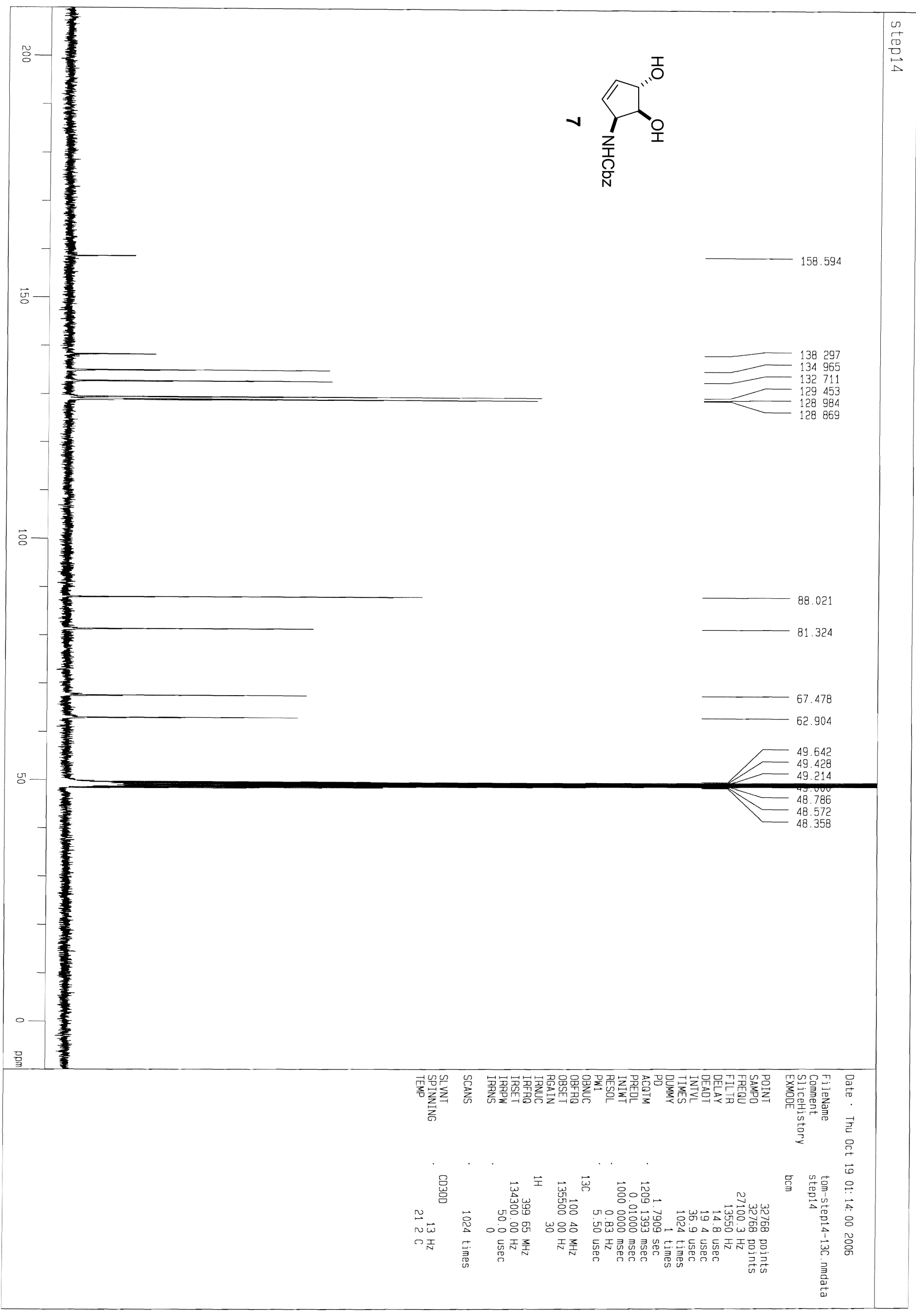

37 


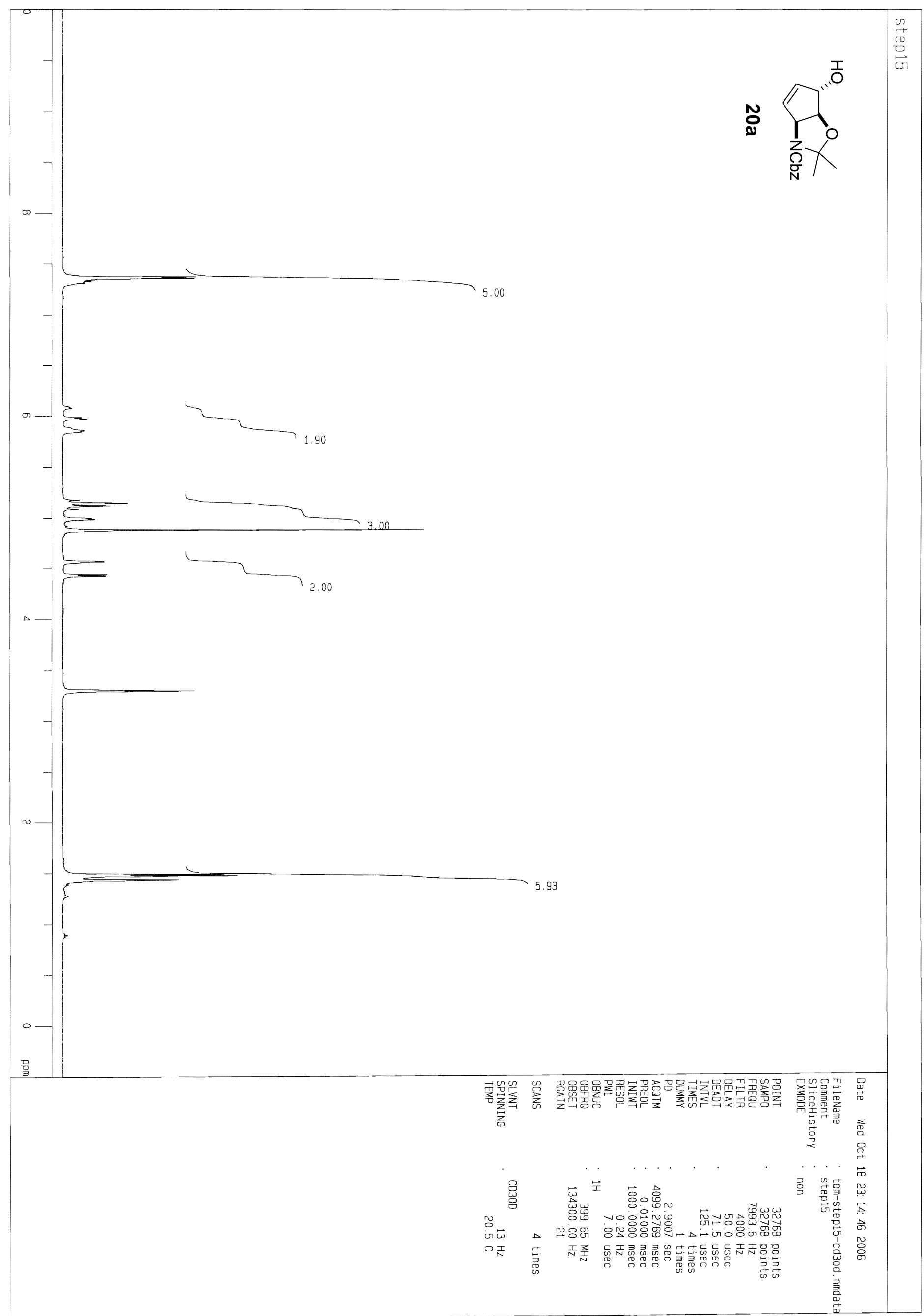




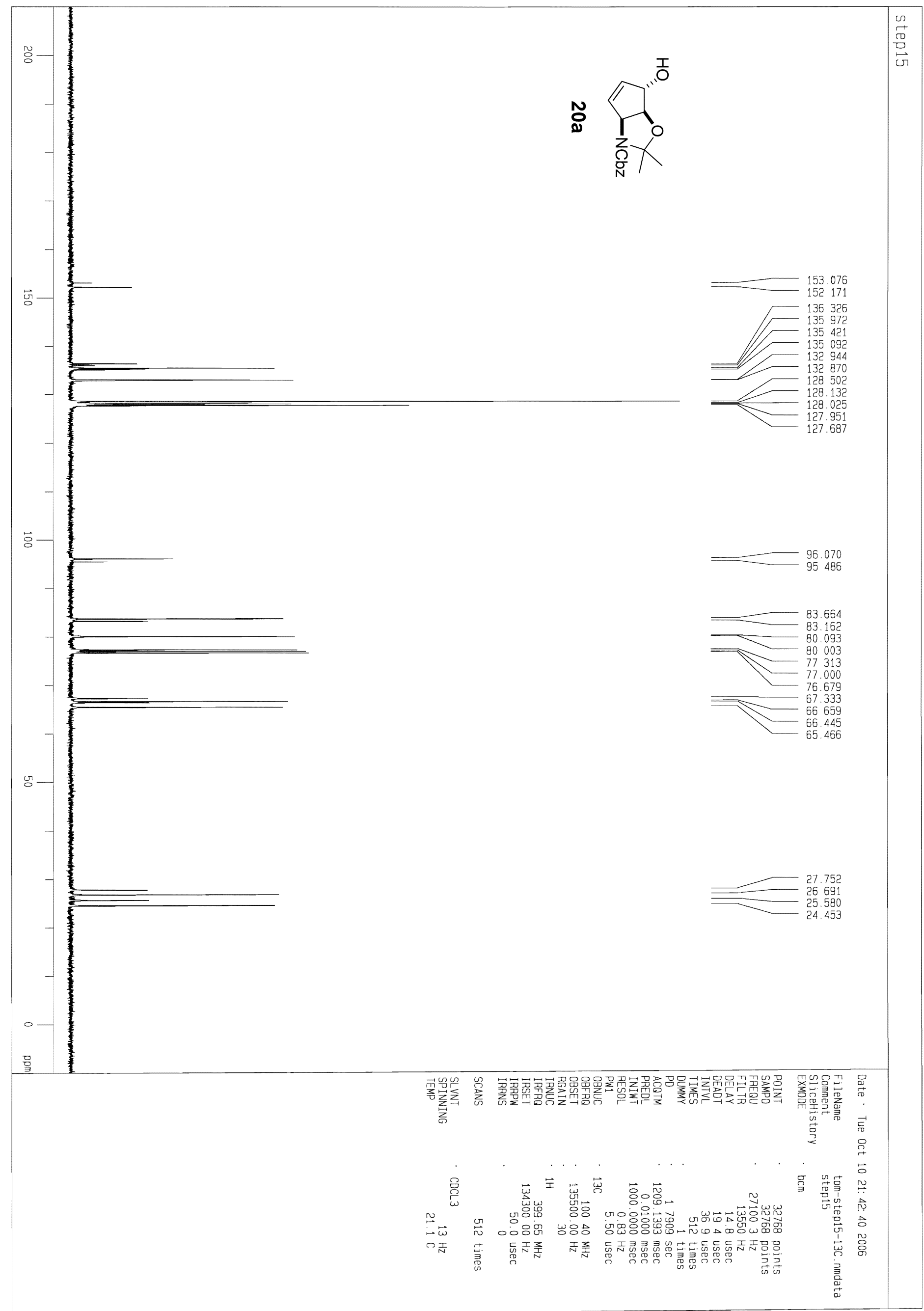




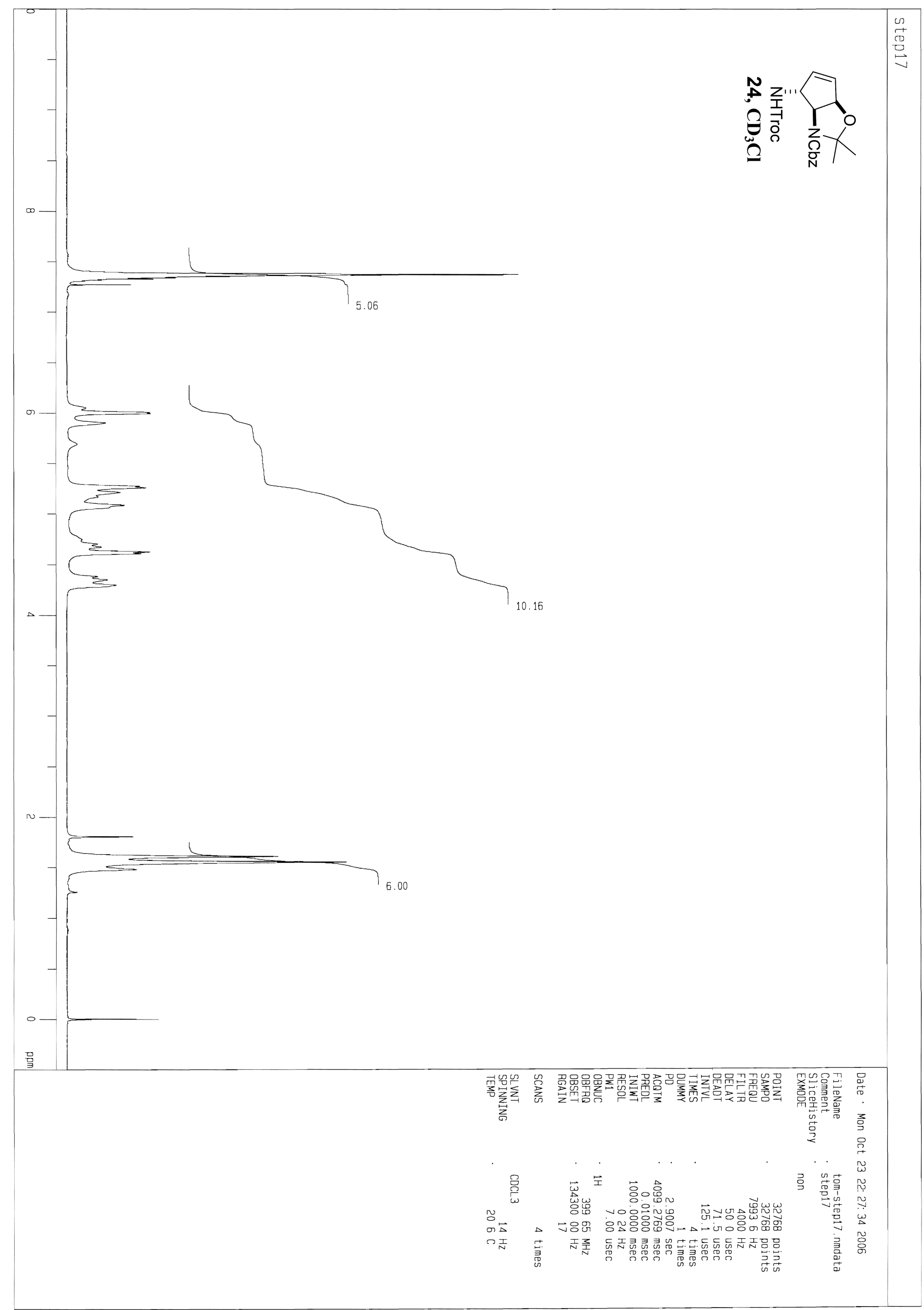




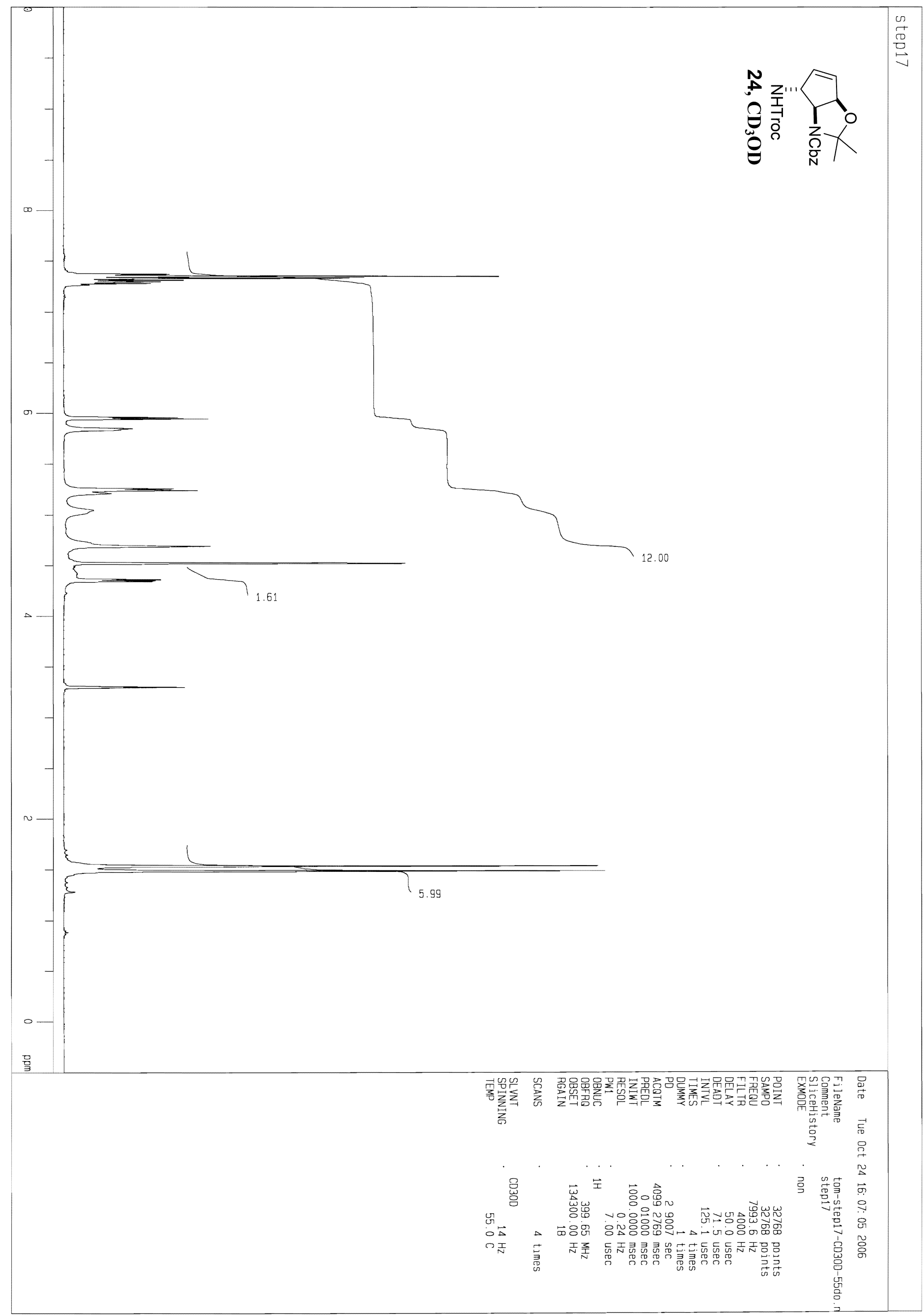




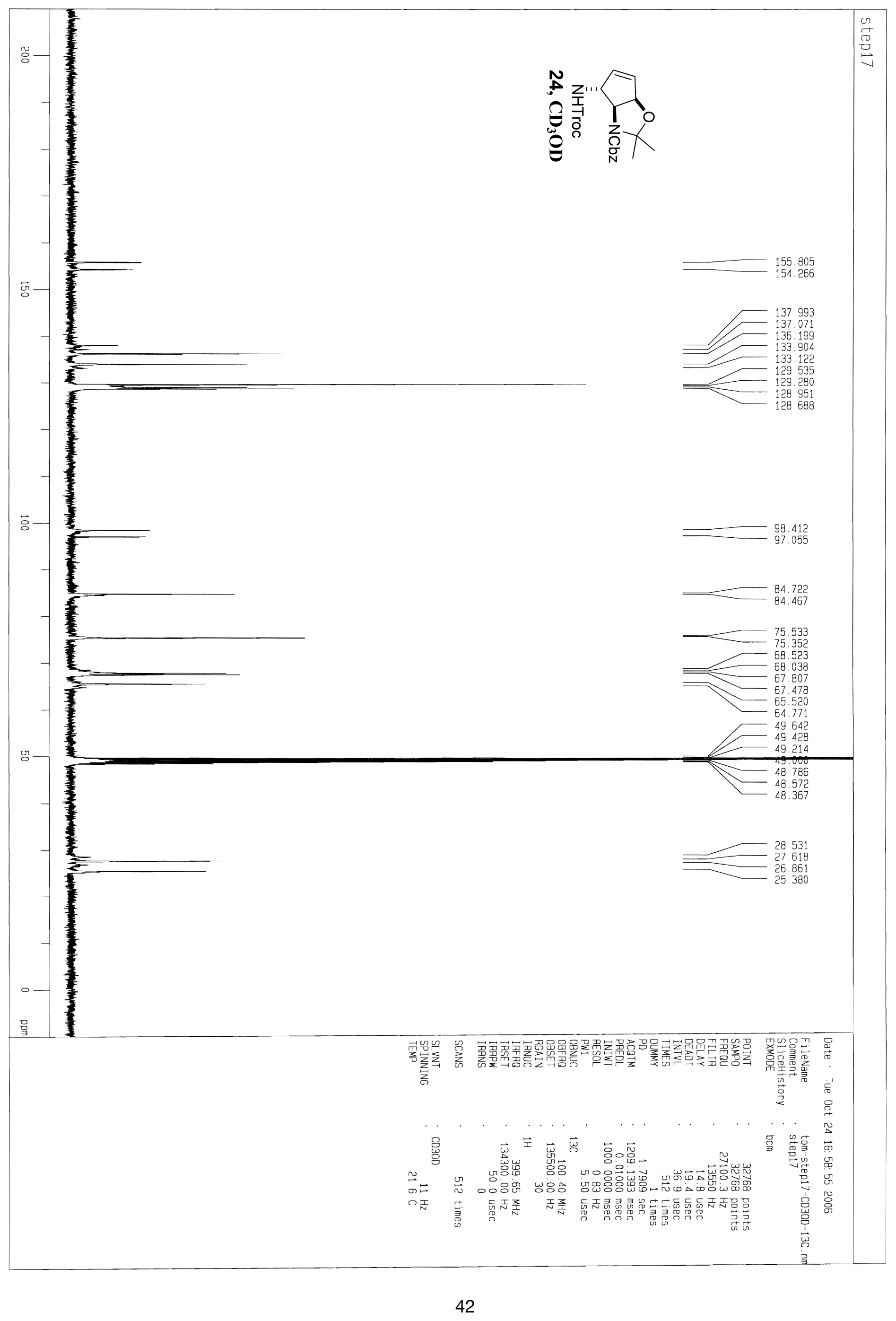




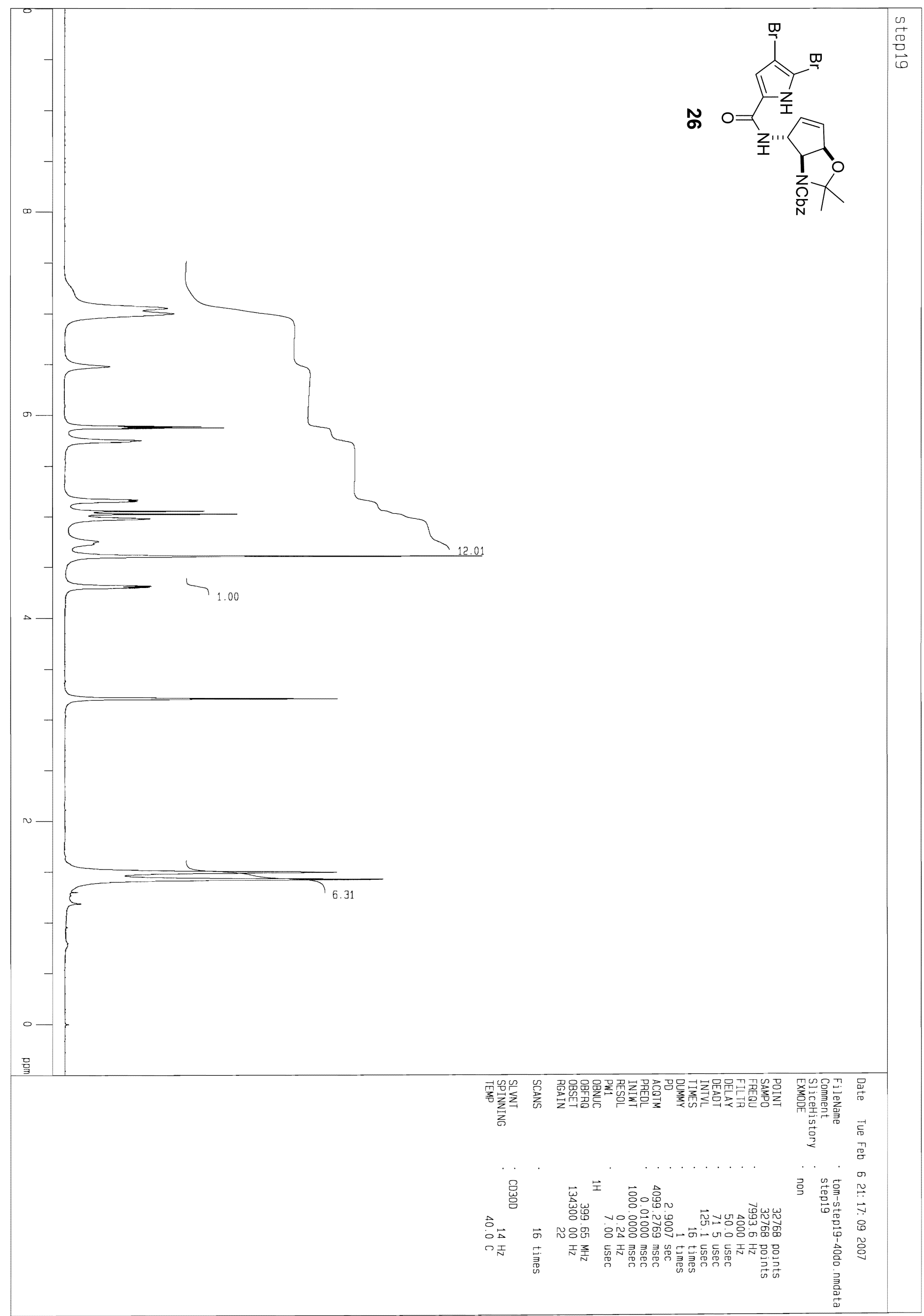




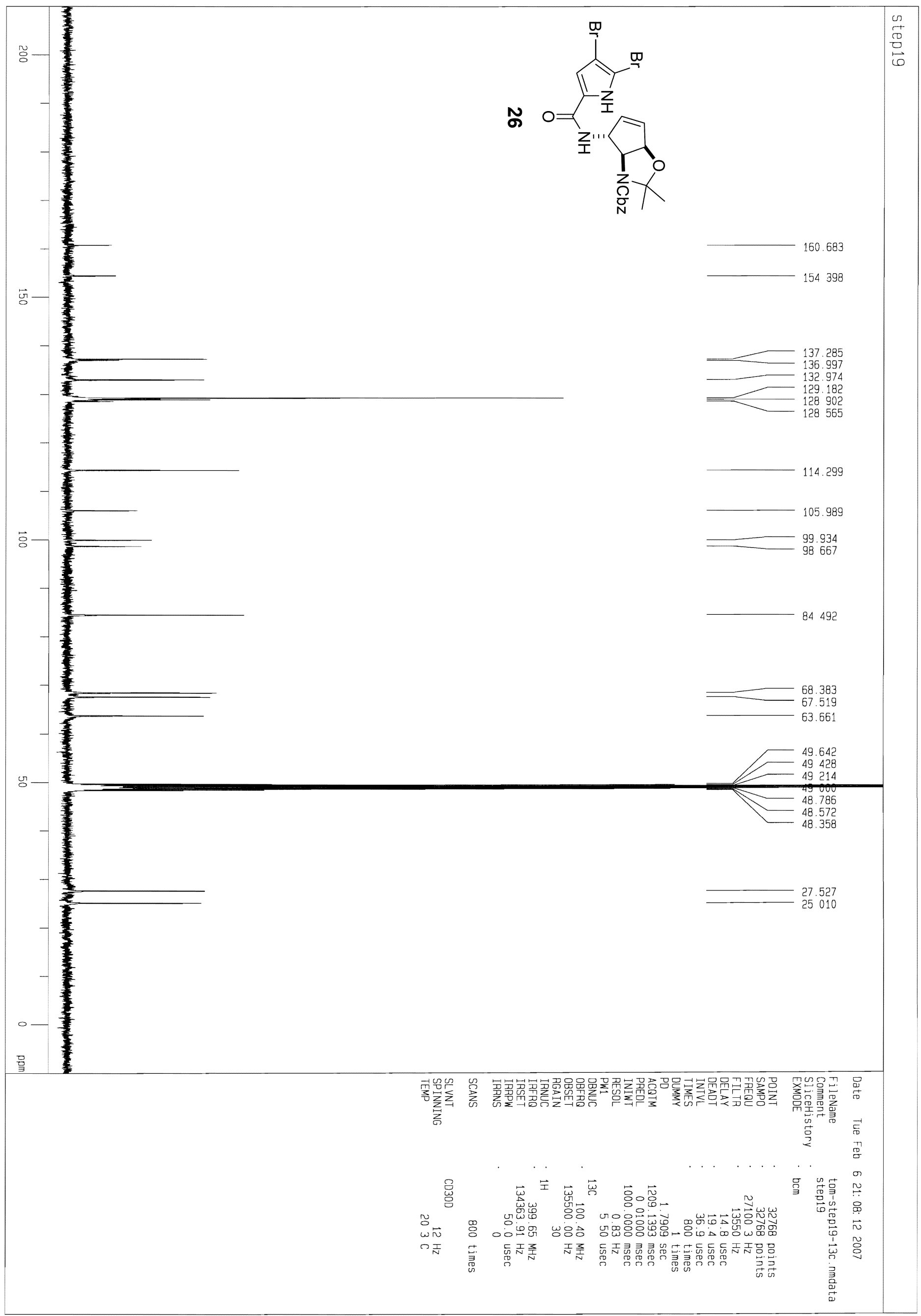




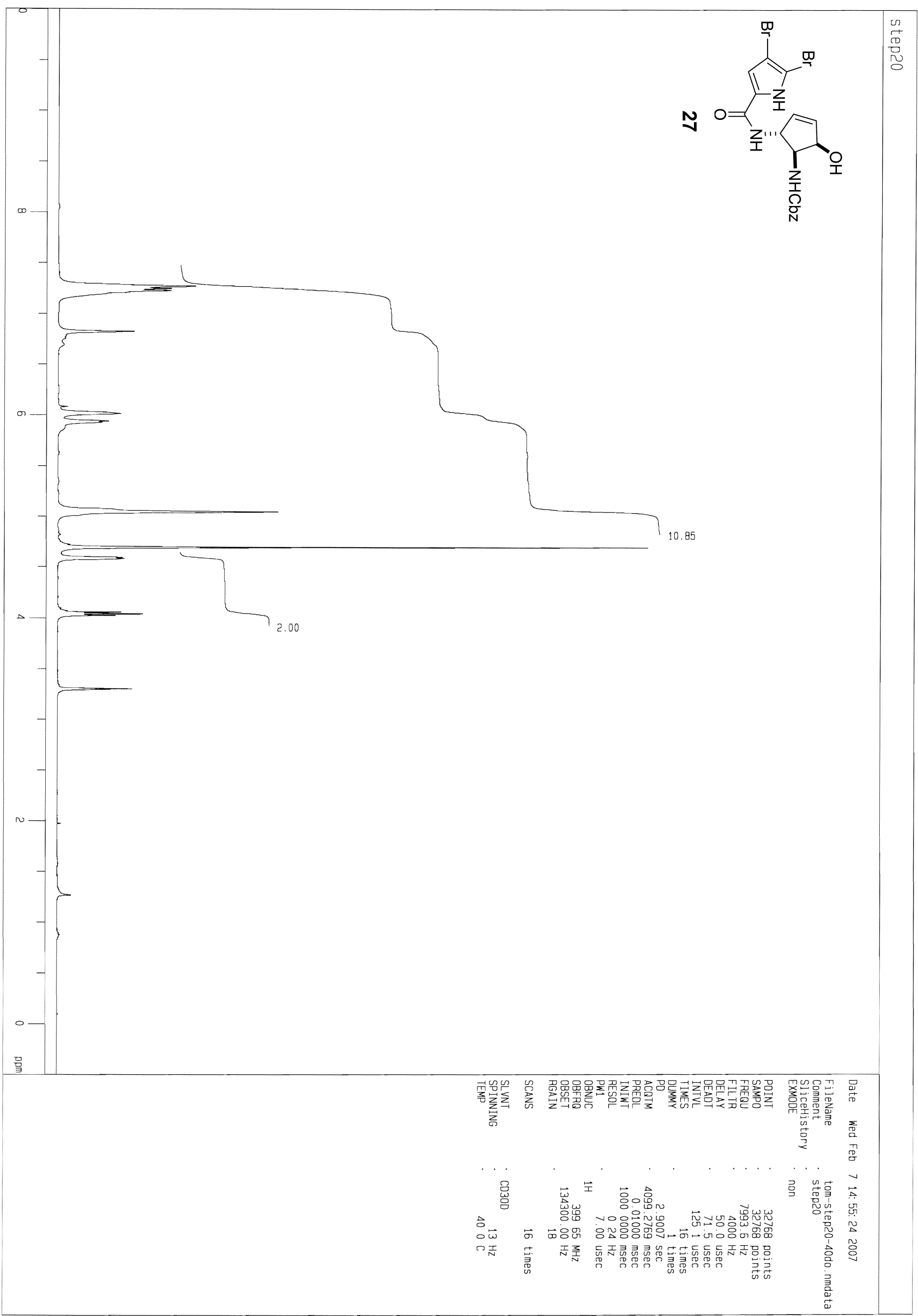




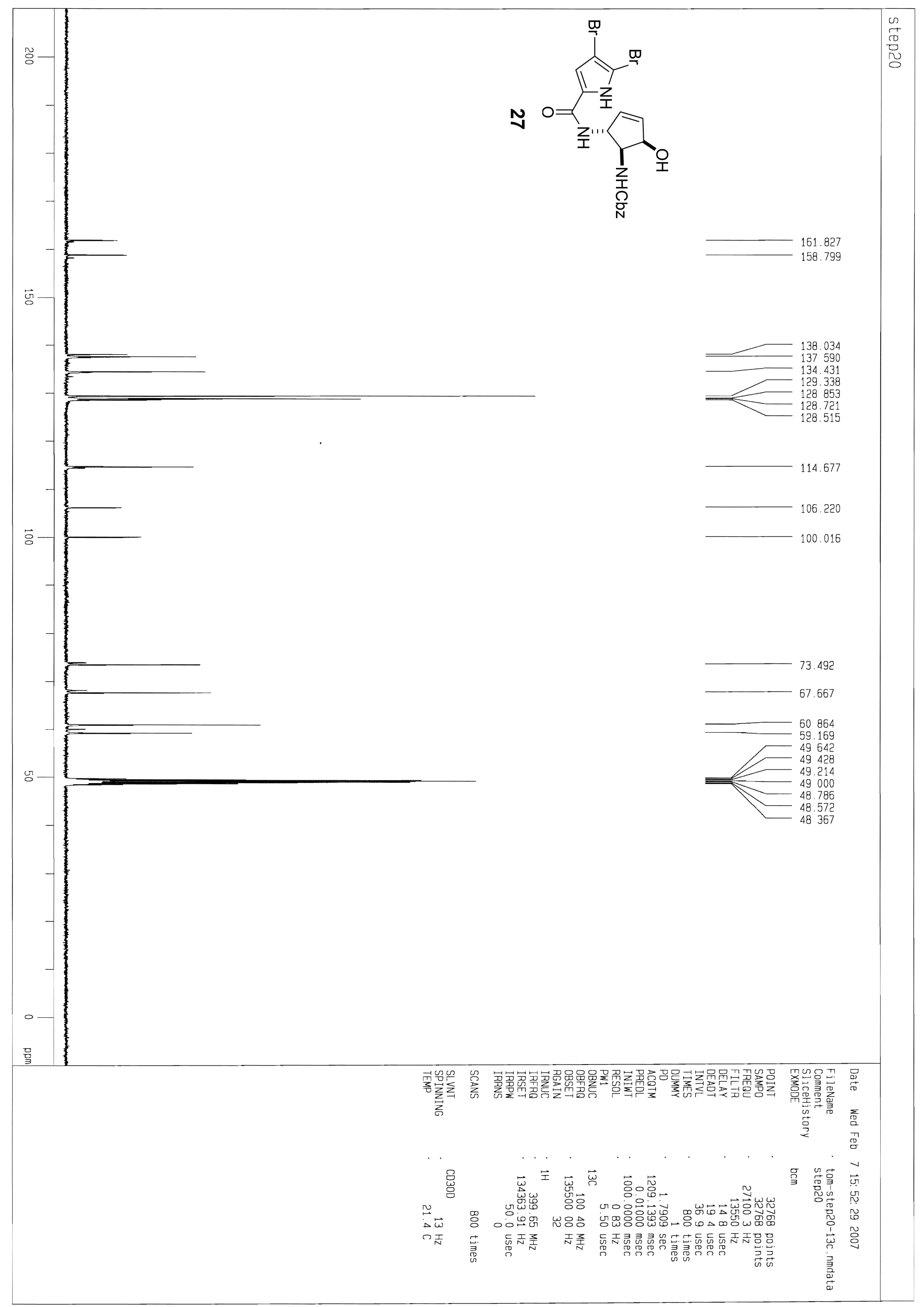




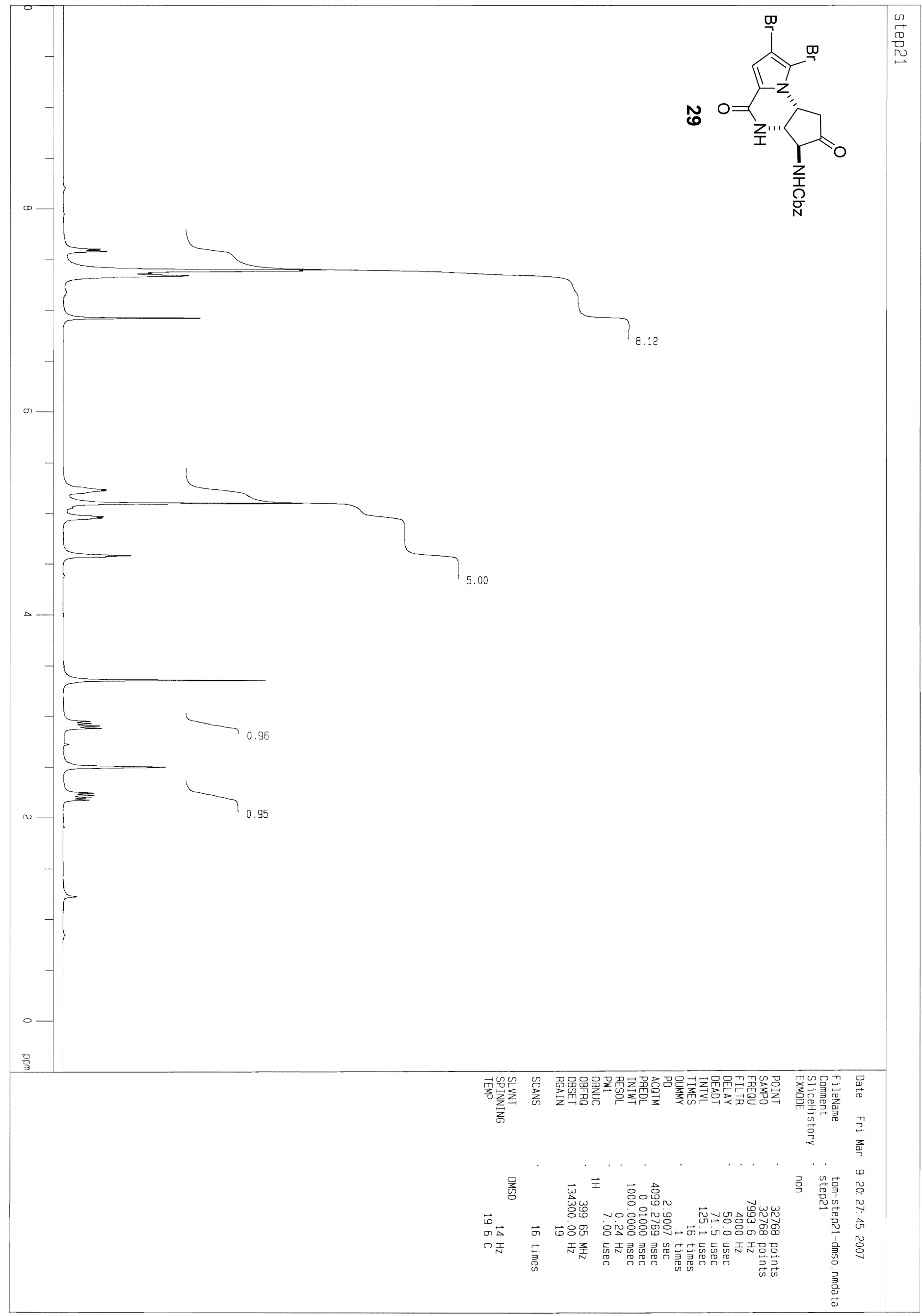




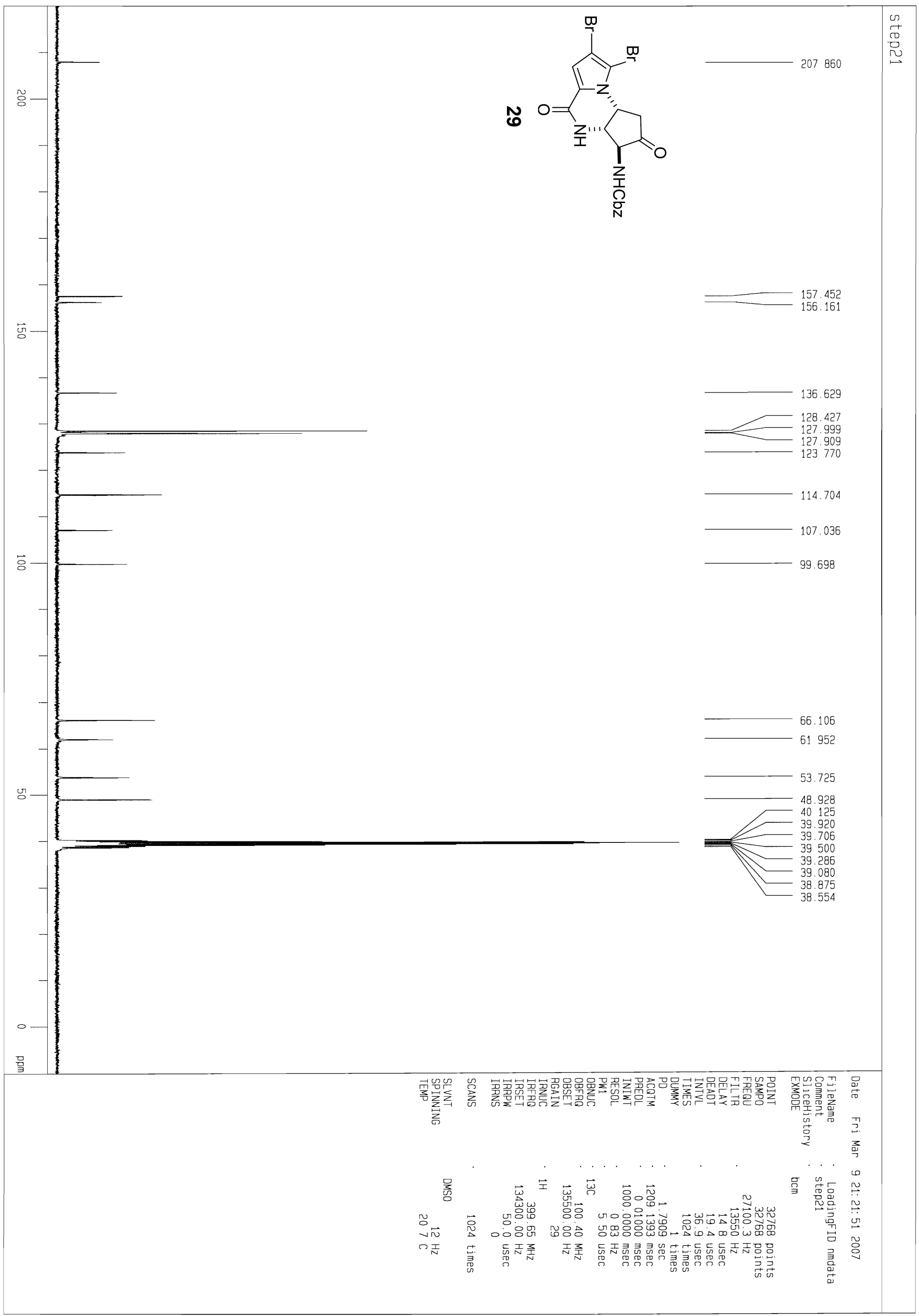




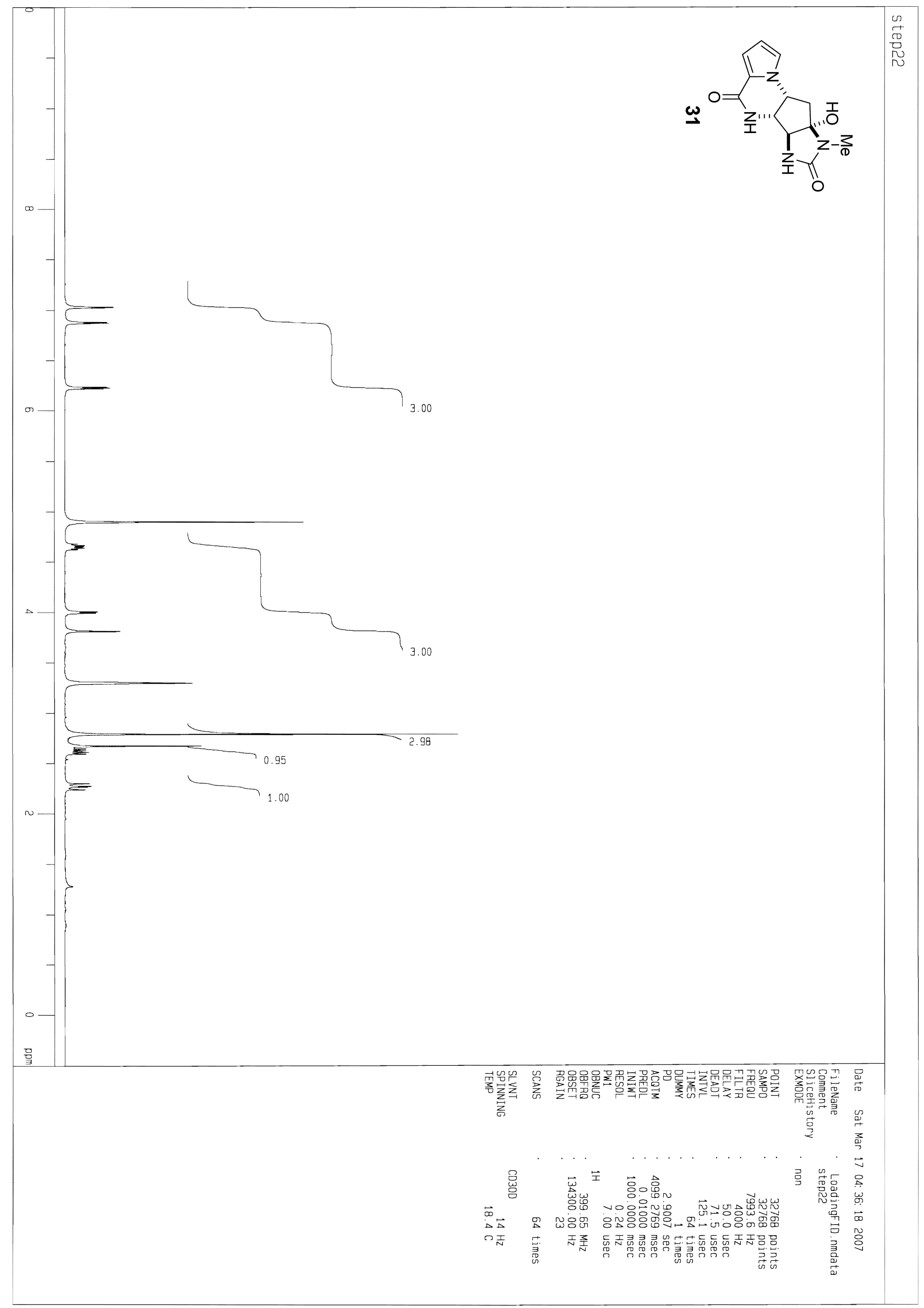




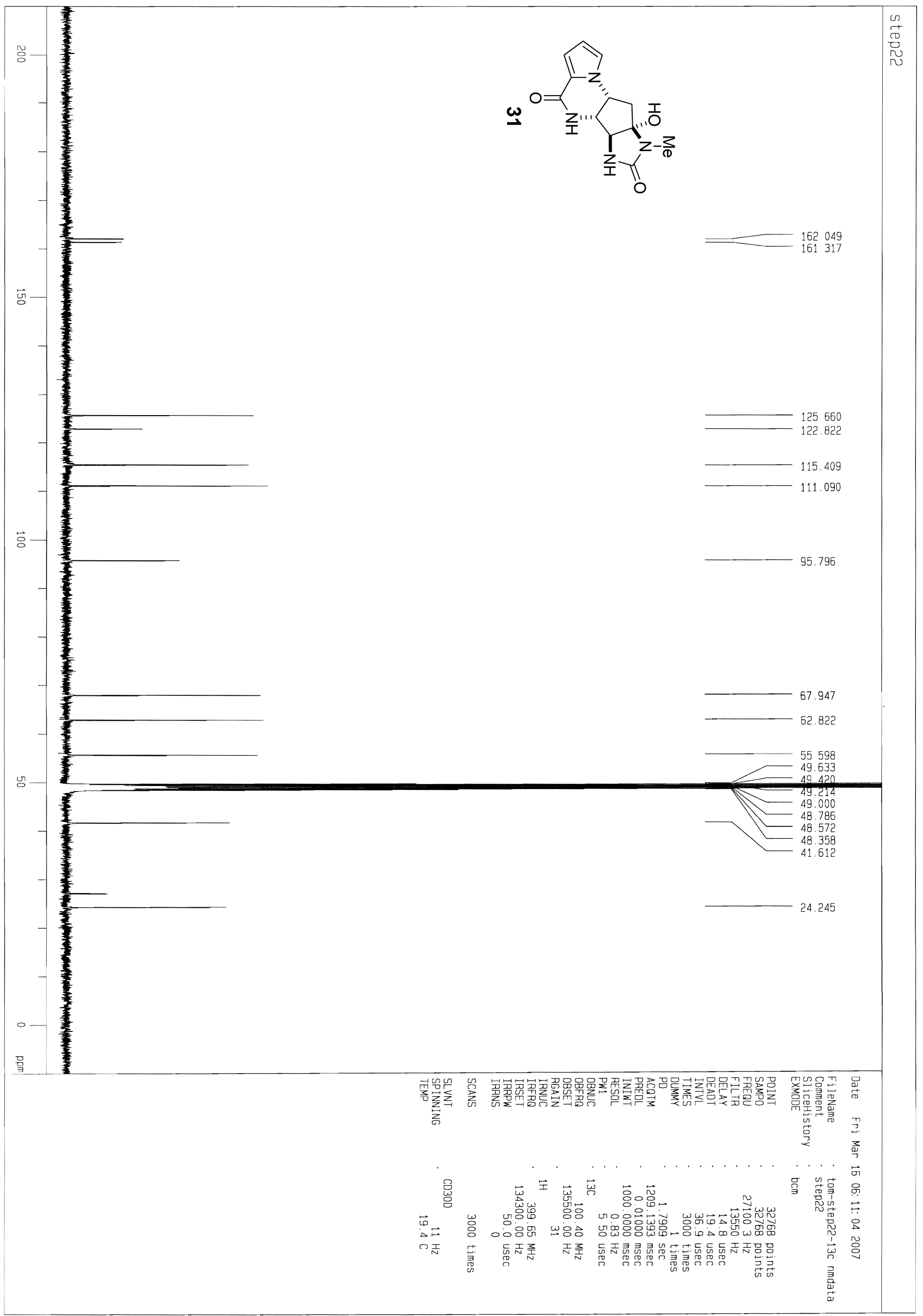




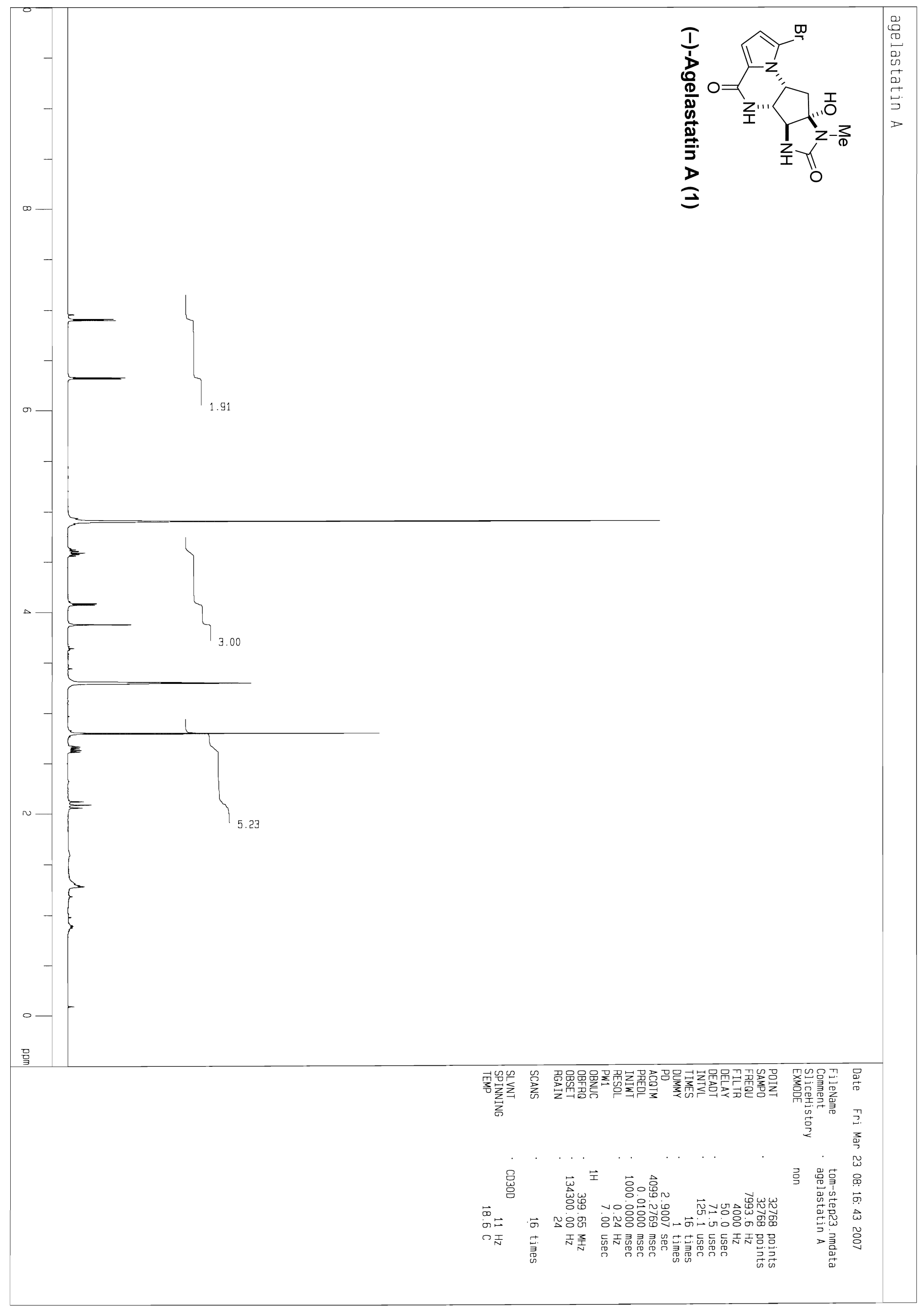




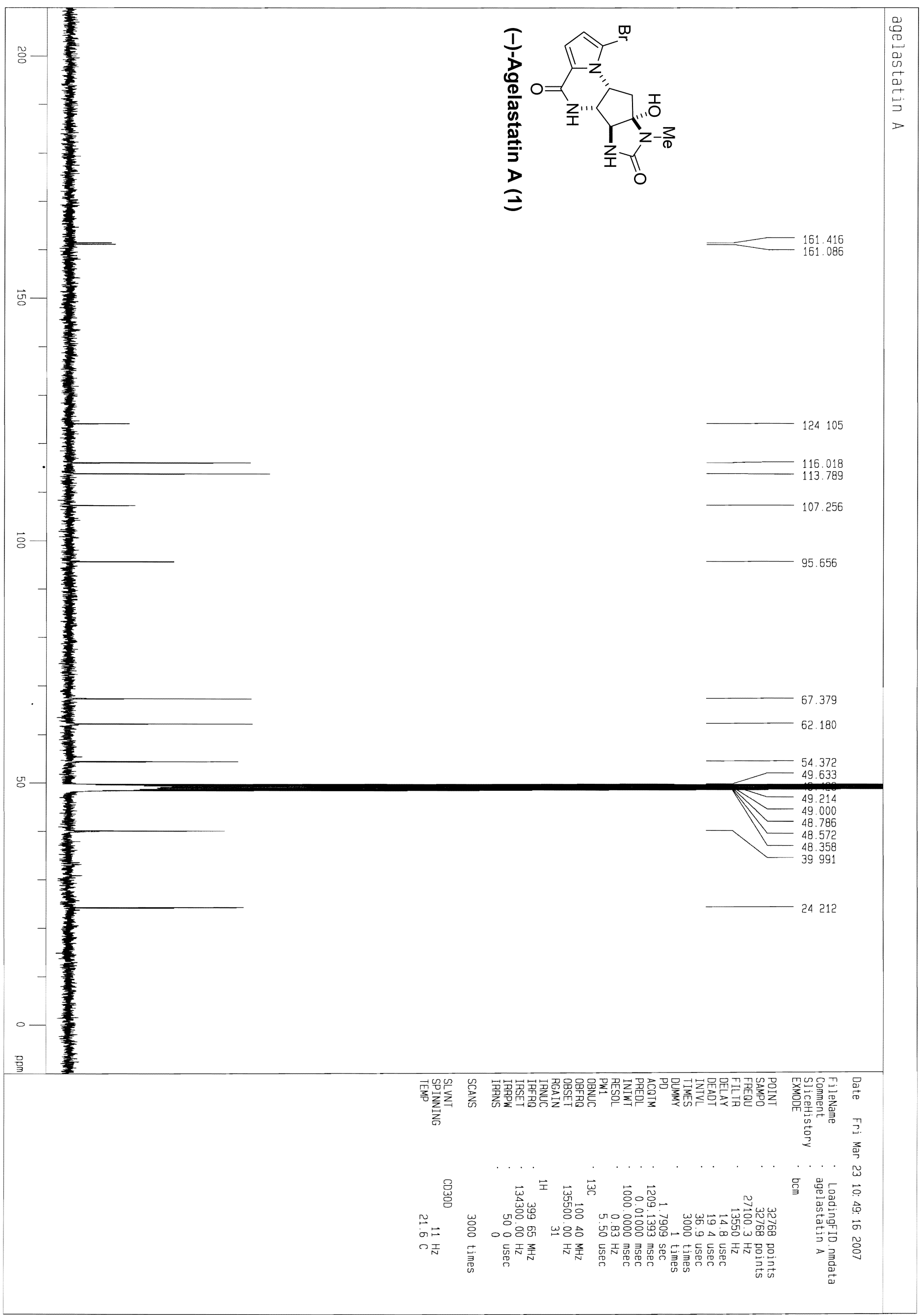

